\title{
WestVirginiaUniversity
}

THE RESEARCH REPOSITORY @ WVU

Graduate Theses, Dissertations, and Problem Reports

1998

\section{Processing resources, cautiousness, memory self -efficacy, and age differences in free recall}

Wei Huang

West Virginia University

Follow this and additional works at: https://researchrepository.wvu.edu/etd

\section{Recommended Citation}

Huang, Wei, "Processing resources, cautiousness, memory self -efficacy, and age differences in free recall" (1998). Graduate Theses, Dissertations, and Problem Reports. 949.

https://researchrepository.wvu.edu/etd/949

This Dissertation is protected by copyright and/or related rights. It has been brought to you by the The Research Repository @ WVU with permission from the rights-holder(s). You are free to use this Dissertation in any way that is permitted by the copyright and related rights legislation that applies to your use. For other uses you must obtain permission from the rights-holder(s) directly, unless additional rights are indicated by a Creative Commons license in the record and/ or on the work itself. This Dissertation has been accepted for inclusion in WVU Graduate Theses, Dissertations, and Problem Reports collection by an authorized administrator of The Research Repository @ WVU.

For more information, please contact researchrepository@mail.wvu.edu. 


\title{
PROCESSING RESOURCES, CAUTIOUSNESS, MEMORY SELF-EFFICACY, AND AGE DIFFERENCES IN FREE RECALL
}

\author{
By \\ Wei Huang \\ Dissertation \\ Submitted to \\ The Eberly College of Arts and Sciences \\ at \\ West Virginia University \\ in partial fulfillment of the requirements \\ for the degree of \\ Doctor of Philosophy \\ in \\ Life-span Developmental Psychology \\ Morgantown, WV \\ 1998 \\ Committee Chair: Hayne W. Reese, Ph.D.
}




\section{Acknowledgments}

I first want to express my appreciation and thanks to Dr. Hayne W. Reese for his guidance, insight, and confidence. Discussions with him helped me understand the literature and refine my research ideas. As my adviser and dissertation Chair, Hayne not only helped me become familiar with the methodology in the area, but also provided me with the grand picture of cognitive aging and how my study fits into this field. I also greatly appreciate Drs. Stan Cohen, Barry Edelstein, Connie Toffle, and Dick Walls for their insightful suggestions and discussion on many aspects of my dissertation.

I am indebted to Kimberly Bauerlein, Roxanne Baker, Christa Caton, and Carrie Ball for their assistance in data collection. Their efficient and courteous interaction with both young and old participants made collecting data easier than it could have been in Morgantown. Their effort facilitated my progress.

I would like to acknowledge the support of the Doctoral Dissertation Research Award from West Virginia University Academic Affair Office and the Psychology Department's Alumni Fund, which covered the costs of this study.

At last, but not at least, I thank a number of loving people in my life whose support gave me the constancy and confidence I needed to study in a foreign country and complete this work. My father, mother, and sister always asked me about my study and my progress. My wife, Wei Jian, always encouraged me, and sacrificed for me. Our first child, Alice Huang, now is 16 months old. She is the witness for the whole progress of my dissertation. She has been giving me lots of joys and additional homework, relearning Developmental Psychology. I dedicate my dissertation to my wife and daughter. 


\section{TABLE OF CONTENTS}

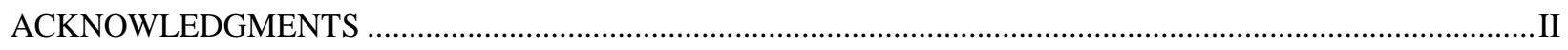

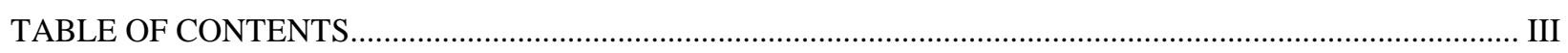

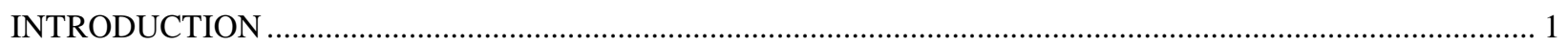

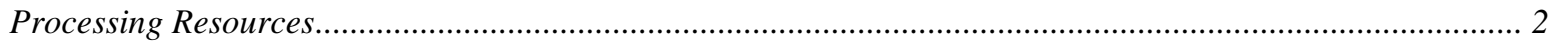

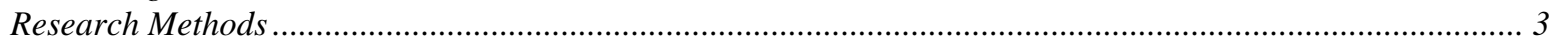

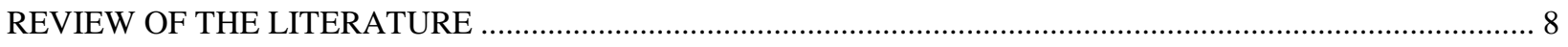

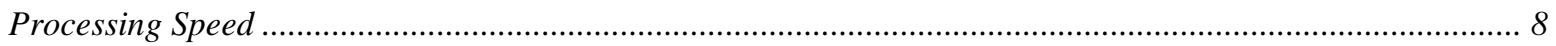

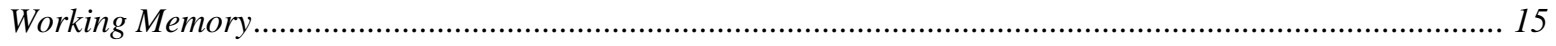

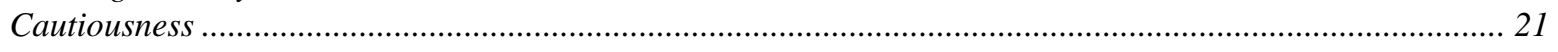

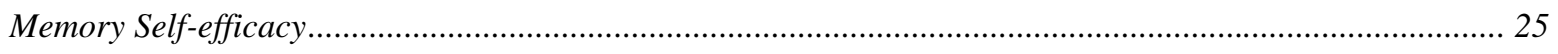

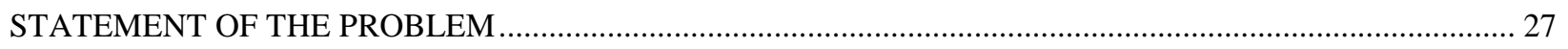

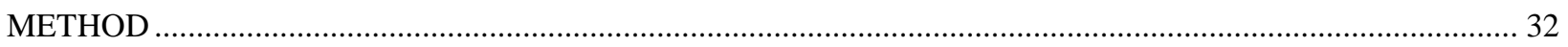

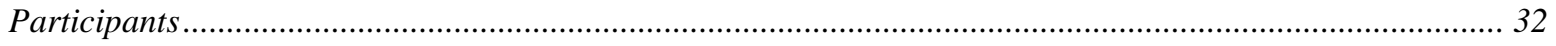

Experimental Manipulations …………............................................................................................ 32

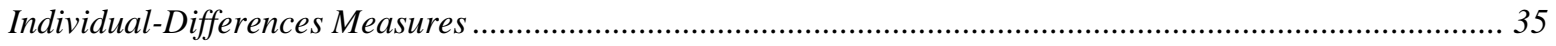

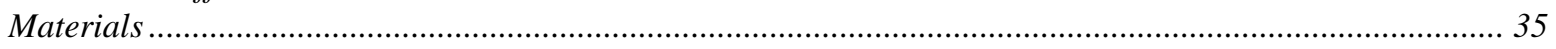

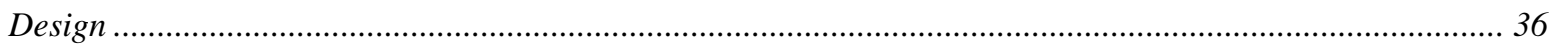

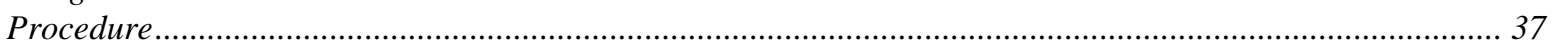

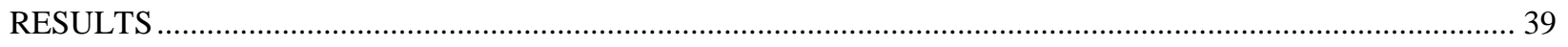

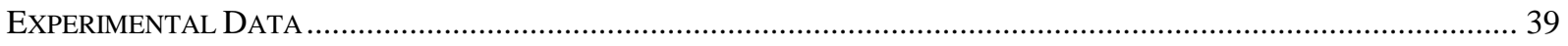

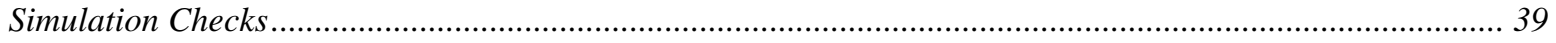

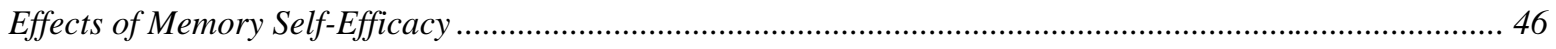

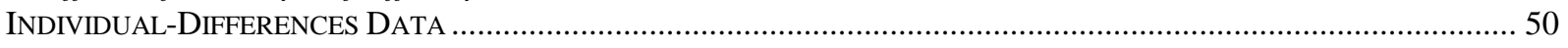

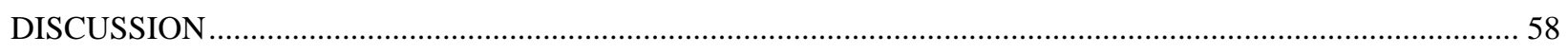

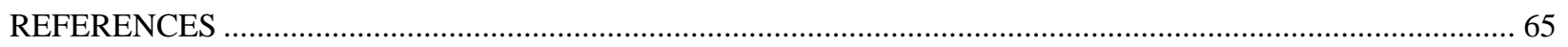

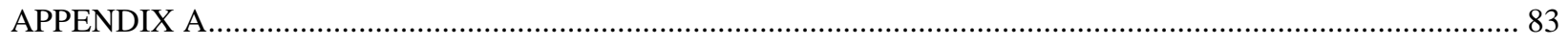

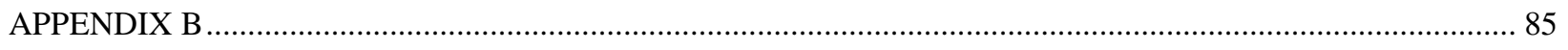

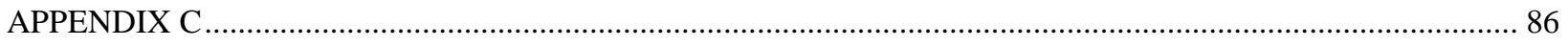

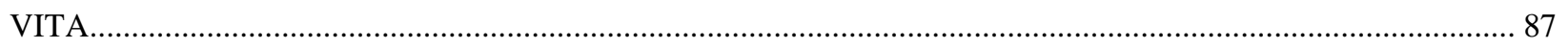

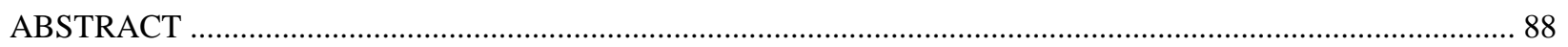

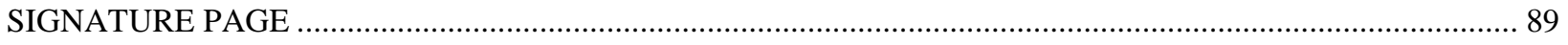


Processing Resources, Cautiousness, Memory Self-efficacy, and Age Differences in Free Recall Introduction

A well-documented finding in developmental psychology is that older adults have poorer performance on a number of memory tasks, such as free recall, cued recall, word recognition, spatial memory, and some other everyday memory tasks. However, age differences in some types of memory tasks, such as picture recognition, prospective memory, and implicit memory are very small, or not found at all. Competing hypotheses about the mechanisms underlying this pattern of data have been proposed (Light, 1991). One of the leading hypotheses on the aging memory phenomena is the processing resource hypothesis (Craik \& Byrd, 1982). Craik and Byrd (1982) suggested that older adults have limited mental energy or processing resource and are deficient in self-initiated processing in which more processing resource is needed. They noted that older adults perform most poorly on free-recall tasks with high processing resource demand, and perform best on recognition, which demands fewer resources. The processing resources have often been operationalized as processing speed (Salthouse, 1991) and working memory (Baddeley, 1986). Abundant evidence shows that both speed and working memory are important for aging memory, but data on how the two variables interact with each other and how the two variables interact with other variables are still unclear. The aim of the present study was to use both experimental and individual-differences strategies to provide convergent evidence for the effects of speed and working memory on age differences in free-recall. In addition, the present study dealt with the interface between cognitive functioning and psychosocial aspects of old age. Memory self-efficacy and cautiousness were included in this study. Special emphasis was given to the interaction between processing resources and social variables that might have implications 
for older adults' memory performance.

\section{Processing Resources}

The notion that cognitive resources are limited has been used since William James (1905/1981). However, the concept of processing resource has been only vaguely defined. In the 1970s and the early 1980s, the processing resource often referred to was attention. For example, Kahneman (1973) hypothesized that mental operations differ in the amount of attention they require. Norman and Bobrow (1975) further distinguished between data-limited and resourcelimited processes. They drew an analogy between human cognitive resources and other information processing devices, such as memory in computers. According to Norman and Bobrow (1975), the processes are resource-limited if an increase in the amount of processing resources results in improved performance. They concluded that processing overload should not cause failure, but simply a decrease in performance. Navon (1984) summarized the status of resource theory and pointed out that using processing resource as an intervening variable allowed explanation and predication of a wide range of empirical observations.

In the late 1980s and the 1990s, research on processing resources was generally consistent with Navon's (1984) position. Kyllonen and his colleagues showed that working memory capacity, processing speed, and previously acquired knowledge can be viewed as processing resources that can be applied to performance on a wide range of tasks (Kyllonen, 1993, 1995; Kyllonen \& Christal, 1991). These resources have been shown to have construct and predictive validity for cognitive performance in a variety of tasks, such as associative learning (Kyllonen, Tirre, \& Christal, 1991), skill acquisition (Pena \& Tirre, 1992; Shut \& Kyllonen, 1990 Woltz, 
1988), and logical reasoning (Kyllonen \& Christal, 1991; Kyllonen \& Stephens, 1990). In cognitive aging research, the processing resource perspective has become a central feature of explanation of age-related deficits in cognitive performance (Kausler, 1994). The essence of the processing resource perspective is that many age-related differences in cognitive performance can be attributed to age-related differences in a few general variables or mechanisms (Salthouse, 1991). Presumably, the number of resources is much smaller than the number of age-related processing components. Thus, one appealing feature of the processing resources perspective is its likelihood to provide more parsimonious and integrative descriptions and explanations of cognitive aging phenomena. Although the exact nature of processing resource still remains vague and controversial, many researchers have accepted the merits of using processing resources in explaining age-related differences in cognitive performance (Kausler, 1994; Salthouse, 1991). Research data have indicated that age-related variance in a range of reasoning, spatial ability, associative learning, declarative learning, memory, and language comprehension tasks can be accounted for by processing speed, working memory capacity, or a combination of these factors as processing resources.

\section{$\underline{\text { Research Methods }}$}

Experimental method. One approach to studying the role of processing resources in age differences in cognitive performance is to manipulate the quantity of resources. Two experimental strategies have been used to implement such a manipulation. One is imposing tasks with higher resource demands on younger adults; the other is reducing resource demands in older adults. The former is often called the simulation strategy (Baltes \& Goulet, 1971; Baltes, Reese, 
\& Nesselroade, 1988; Salthouse, 1991). The latter is called the environmental support strategy (Craik, 1986).

The simulation strategy attempts to simulate the hypothesized resource limitation of older adults in younger adults by increasing resource demands on younger adults and comparing the effects of such manipulation with the effects of normal aging on performance. To the extent that age differences in performance are modeled by the manipulation, one can make the argument that it provides evidence that the age differences are due to reduced processing resources in older adults. If the simulation is successful, then younger adults under simulation should behave similarly to older adults under normal conditions. However, because quantitative levels of performance can be altered in many ways, results from attempted simulations would not be very convincing unless the same qualitative pattern of preserved and impaired processes is evident among younger adults in the conditions of simulation, and among older adults under normal conditions. The more aspects of performance shown to be equivalent, the more confidently one can conclude that the simulation was valid and that the manipulated resource is critical. That is, performance should be qualitatively similar between the older adults and the simulation group (Salthouse, 1991), and multiple measures of performance should all lead to the same conclusion. The merit of the simulation approach is its potential to suggest an explanation rather than merely a description of developmental processes.

One recent study that utilized the simulation strategy was reported by Mäntylä and Bäckman (1992). They studied age differences in memory for objects in real-world settings. Specifically, they examined age differences in the consistency effect--that memory for items inconsistent with expectations are better remembered than items consistent with expectations. 
Although older adults showed a similar consistency effect as younger adults in general, they did not show such an effect when asked to recognize specific instances (e.g., a black versus a gray typewriter). This same pattern was obtained with a group of younger adults who were required to count backward by sixes from a random 3-digit number during encoding. That is, they showed a general consistency effect, but not for specific details, just like older adults.

The second strategy that relates to the experimental manipulation of resource quantity is attempting to minimize the influence of the critical resources among older adults. The manipulation in this strategy is opposite to the simulation strategy. If tasks can be modified to require less demand on a critical processing resource, then one can expect that the performance of older adults will improve to a level closer to the normal level of younger adults. Typical implementation of such a strategy is called environmental support (Craik, 1986). To the extent that tasks providing environmental support require fewer processing resources than those without such support, one would expect age differences to be minimized because the reduced requirements are more likely to be within the capacities of older adults.

Results from a number of experiments produced mixed data on the effects of environmental support on memory performance. Some studies showed that older adults benefited more from encoding and retrieval support. For example, West and Boatwright (1983) presented words with semantic or acoustic orienting tasks, and tested retention in recognition and cuedrecall tests using the original semantic or acoustic description as cues. There were no age differences in recognition, and the age-related decrement in cued recall was least in the condition that paired a semantic orienting task with semantic cues at recall. In contrast, when an acoustic orienting task was paired with acoustic cues the older adults recalled more words than the young. 
The authors concluded that older adults have difficulty using effective semantic information spontaneously at encoding and retrieval, but can use it, thereby reducing age-related losses, when the tasks supply sufficient constraint and guidance. Some other studies support the notion that support is particularly effective when the context and target are well integrated (Bäckman, 1986; Park, Smith, Morrell, Puglisi, \& Dudley, 1990; Rankin \& Collins, 1986; Rankin \& Firnhaber, 1986). A large number of studies suggested that the young and the old benefit equally from supporting manipulations. For example, Park, Puglisi, and Smith (1986) found that older and younger adults benefited equally from the provision of more elaborate pictorial embellishment in recognition tasks. Similar results were found in other studies when words rather than pictures were used as stimuli (Rankin \& Collins, 1985). However, some studies found that younger adults benefited more from support than older adults (Erber, Herman, \& Botwinick, 1980; Craik \& Rabinowitz, 1985; Treat \& Reese, 1980).

Individual-differences method. The individual-differences method attempts to determine the proportion of age differences in measures of cognitive performance that can be accounted for by controlling the age differences associated with processing resources. This method has often been called statistical control of processing resources (Salthouse, 1991). Salthouse (1991) outlined four steps to estimate the relative contribution of processing resources to age differences in cognitive performance. The first step is to compute the variance shared by age and cognitive performance but not by processing resources. Second, the total variance common to age and cognitive performance is determined. Third, the proportion of the common variance not shared with processing resources is calculated by dividing the first value by the second value. Finally, the proportion of the shared age-cognition variance also common to processing resource is 
computed by taking the complement of the value from the third step. There are several statistical procedures that can be used to estimate the relative contribution of processing resources.

Hierarchical regression analysis, commonality analysis, and structural equation modeling are the most popular procedures used in the area (see Byrne, 1994; Grimm \& Yarnold, 1995, for detailed descriptions of these procedures).

A number of requirements and assumptions underlie the individual-differences method (Salthouse, 1991). One requirement is that the assessment of cognitive performance and processing resources is reliable and valid. One way to test the validity of hypothetical constructs is to examine the correlation among measures presumed to represent the same constructs. If the correlation among measures is relatively high, then one can be more confident that they are measuring the same construct. The assessment of the construct can also be expected to be more precise and reliable than when a single variable is used in assessing a processing resource (Salthouse, 1991). Another requirement is a larger sample for statistical analysis. Although no absolute minimum number of research participants can be specified, analysis of previous studies with similar types of analysis should provide some ideas of how many participants are needed. One important assumption of most statistical procedures is that there are linear relations between age and resource quantity and between resource quantity and cognitive performance. Results could be misleading and less accurate if the actual relations among these constructs are not linear. Statistical tests of the linearity of functions are available. 
Review of the Literature

\section{Processing Speed}

Processing speed as a processing resource is based on a time analogy in which rate of information processing is critical for many, if not all, cognitive processes (Salthouse, 1991). The basic assumption of processing speed as a processing resource is that more rapid execution of cognitive operations allows more and possibly better processes to be carried out (Salthouse, 1985, 1991). Negative relations between age and measures of processing speed are well documented in the aging research literature (Cerella, 1990; Salthouse, 1996). Therefore, older adults' impaired cognitive processes have been attributed to their slower rate of processing, which has been observed in both laboratory settings and everyday activities. Using speed as a processing resource also has historical roots in early arguments that neural transmission slows with aging. It is hypothesized that such slowing is due to a number of factors, including increasing neural noise with aging (Birren, 1964, 1965; Birren, Riegel, \& Morrison, 1962; Cerella, 1985; Crossman \& Szafran, 1956; Gregory, 1957; Salthouse \& Lichty, 1985; Welford, 1958), slowing of transmission of neutral impulses across synapses (Birren, 1974), broken or attenuated neural connections (Cerella, 1990), weakened linkage strength between connections (Mackay \& Burke, 1990), and an increase in the proportion of information lost at each step of processing (Salthouse, 1985).

Although the causes of slowing with aging are still under investigation, research has shown that aging is accompanied by slower responding in almost every task in which response speed has been assessed. In the domain of memory, results have shown that older adults have a 
slower rate of rehearsal (Salthouse, 1980; Sanders, Murphy, Schmitt, \& Walsh, 1980), a slower rate of scanning and retrieval (Anders \& Fozard, 1973; Anders, Fozard, \& Lillyquist, 1972; Cerella, 1985; Cerella, Poon, \& Williams, 1980; Eriksen, Hamlin, \& Daye, 1973; Ford, Roth, Mohs, Hopkins, \& Emery, 1989; Madden \& Nebes, 1980; Marsh, 1975; Plude \& Hoyer, 1981; Plude, Hoyer, \& Lazar, 1982; Puglisi, 1986; Salthouse \& Somberg, 1982a, 1982b; Strayer, Wickens, \& Braune, 1987; Thomas, Waugh, \& Fozard, 1978), a slower rate of responding in primary and secondary memory tasks (Waugh, Fozard, \& Thomas, 1978), and a slower rate of accessing abstract codes (Guttentage \& Madden, 1987; Lorsbach \& Simpson, 1984, 1988; Madden et al., 1989; Petros, Zehr, \& Chabot, 1983). Studies also suggested that slower processing resulted in shallower encoding (Salthouse, 1980; Salthouse \& Kail, 1983; Wingfield, 1980; Wingfield \& Stine, 1989), and lower levels of many types of organization (Kirchner, 1958; Salthouse, 1980).

Slower rate of processing has also been attributed to other cognitive processes. For example, slower alternation between simultaneous activities has implications for difficulties in divided attention in the elderly (Talland, 1967, 1968). Slower rates of perceiving, accessing, and integrating new and stored information has also been linked to problems in comprehension (Birren \& Riegel, 1962; Cohen, 1979; Salthouse \& Kail, 1983; Spilich, 1985; Stine, Wingfield, \& Poone, 1986). A number of researchers also speculated that slower rate of processing may influence some higher-level processes by reducing the likelihood of higher levels of integration and abstraction, which often depend upon the completion and efficiency of earlier processing (Alpaugh \& Birren, 1977; Birren, 1955, 1964; Birren \& Riegel, 1962; Bromley, 1967; Fozard \& Thomas, 1975; Heron \& Chown, 1967; Jones, 1956; Salthouse, 1982, 1985, 1988; Witt \& 
Cunningham, 1979).

Cerella $(1980,1990)$ pointed out that older adults have a slower rate of processing proportionately slower than that of younger adults in completing the same process. That is, the reaction time of the elderly is linearly related to the reaction time of the young, as revealed by plotting the mean scores of the elderly as a function of the mean scores of the young. The slope of the linear function reflects the proportional decrease of speed with aging. This kind of plot is now known as a Brinley-plot (Brinley, 1965).

Researchers have agreed that perceptual speed is more important than sensory-motor speed in aging cognition; thus perceptual speed measures should be used in investigating the mediating role of speed in aging cognition. The hypothesis is that perceptual speed measures reflect the minimum time required for executing a variety of different internal cognitive operations. It is different from sensory-motor speed because the latter reflects the rate of receiving and responding to information (Salthouse, 1991). Salthouse (1992) suggested that speed measures derived from tests with few demands should show a smaller age difference than speed measures derived from more cognitively demanding tests. One of the popular measures of perceptual speed is the Digit Symbol Substitution Test from the WAIS-R. Digit Symbol Substitution test yields several measures, such as Digit Symbol Reaction Time and Letter Symbol Reaction Time.

Salthouse (1996) proposed that two distinct mechanisms - a limited time mechanism and a simultaneity mechanism -- are responsible for the relation between speed and cognition. The assembly line has been used as a metaphor for the limited time mechanism: If relevant operations are not successfully completed within a particular time frame, the quality of the final product is 
likely to be impaired because later processing operations will be either less effective or not completed. A metaphor for the simultaneity mechanism is some type of juggling activity. Based on this mechanism, complex activity requires synchronization of the constituent tasks, and synchronization is easier when the relevant processing operations can be executed rapidly (Salthouse, 1996). However, these assumptions have not been tested experimentally. Nevertheless, given the fact that speed has implications for many cognitive processes, the hypothesis that speed is a processing resource has become very popular in cognitive aging. A number of studies were designed to test the role of processing speed in aging memory; they are reviewed in the following paragraphs.

Experimental data. Very few experiments have been used to test the effect of processing speed on age differences in memory. In an early study, Salthouse (1980) attempted to simulate the effects of a slower rate of rehearsal in a group of younger adults. He hypothesized that younger adults required to remember words with a greater number of syllables might perform like older adults required to remember words with fewer syllables. His rationale was that the rate at which relevant information could be rehearsed is a major factor underlying good memory, and increasing the number of syllables in the to-be-remembered words can modify the rate of rehearsal. Sixty one-syllable and 60 three-syllable words were used in five trials. The presentation duration was 1.5 second with a 2.0-second inter-word interval. As expected, the younger adults outperformed the older adults in both conditions and both groups remembered more one-syllable words than three-syllable words. Similar serial position functions were also obtained in the young and old groups for both types of words. However, the young adults' recall of three-syllable words was better than the older adults' recall of one-syllable words, indicating 
that simulation was unsuccessful.

In a more recent study, Kersten and Salthouse (1993, reported in Salthouse, 1996) found a negatively accelerated relation between accuracy and presentation time, indicating that memory performance became increasingly impaired as presentation speed decreased. In addition, in each presentation condition older adults performed less well than younger adults, suggesting that older adults completed less processing in a given amount of time. Craik and Robinwitz (1985), however, found that increasing presentation-duration for the old did not result in recall performance as good as that of the young in a shorter presentation-duration condition. In addition, in Kersten and Salthouse's (1993) study, the function relating accuracy to rate had an asymptote less than $100 \%$. These results suggested that speed of information processing, such as rehearsal speed, may be an important factor for age-memory relation, but it is not the only one. Individual-differences data. Individual-differences methods have been used extensively to study the effect of processing speed on aging memory. The central question for most of the individual-differences studies is how much age-related variance in memory can be accounted for by the rate of processing. However, research on whether a general speed factor or specific speed factors mediate aging memory has produced mixed results. A number of studies showed that a relatively small amount of the variance associated with each variable was shared with other variables presumed to assess the same speed construct. This result suggests the existence of several independent speed factors (Bashore, Osman, \& Heffley, 1989; Birren, 1965; Birren et al., 1979; Hertzog, 1989; Hertzog, Raskind, \& Cannon, 1986; Salthouse, 1985a; Strayer et al., 1987; Tomer \& Cunningham, 1993; White \& Cunningham, 1987).

Factor analyses supported this argument by showing that speed measures cluster on more 
than one factor. For example, Tomer and Cunningham (1993) included 16 speed measures in a sample of 149 elderly and 147 young adults. Their confirmatory factor analyses revealed five first-order factors -- Symbolic Perceptual Speed, Figural Perceptual Speed, Choice Reaction Time, Sternberg Reaction Time, and Card Sorting. Symbolic Perceptual Speed was indicated by Finding A's, Number Comparison, and Letter Comparison tests. Figural Perceptual Speed included the Identical Pictures and Perceptual Speed tests. Choice Reaction Time included Simple Reaction Time and Choice Reaction Time version 1 and 2. Sternberg Reaction Time included Sterberg's (1975) memory scanning tasks with symbolic contents (word, letter, and number). Card Sorting included tasks involving sorting 52 playing cards into categories. Tomer and Cunningham (1993) also hypothesized three second-order factors -- Perceptual Speed, Reaction Time, and Card Sorting.

A number of other studies support the existence of a general speed factor that mediates age differences in memory (Birren et al., 1962; Laux \& Lane, 1985; Madden, 1989; Salthouse, 1988a; 1996). For example, Salthouse (1996) tested general and specific speed mediation of adult age differences in free recall and serial recall. He included 20 speed measures, such as articulation speed, Pattern Comparison, Letter Comparison, Number Matching, Letter-letter Reaction Time, Symbol-Letter Reaction Time, and Symbol-symbol Reaction Time. Structural equation analyses revealed a single general speed factor. Most of the age-related influences on the individual speed variables were modeled as being mediated through this general speed factor. The analyses also revealed that a large amount of the age-related variance on the speed measures was shared, which supported the existence of a general speed factor. The structural model suggested that age-related effects in the general speed factor mediated the age-related variance in 
memory. A series of hierarchical regression analyses confirmed this suggestion.

The results from Salthouse's laboratory have consistently demonstrated the mediating role of speed in aging memory. For example, Salthouse (1985a) found a correlation of -0.75 between age and free-recall scores, which was reduced to about -0.45 when individual differences in processing speed was controlled. Thus, controlling for the slower processing speed of elderly participants, as operationalized by scores on the Digit Symbol Substitution Test, greatly attenuated the magnitude of the age deficit in free-recall scores. In a later study, Salthouse (1993) tested 305 adults from a wide age range using a task that requiring remember two lists of 12 words each and two speeded paper-and-pencil perceptual comparison tasks involving pairs of letters or pairs of line patterns. The latter two tests presumably measure participants' perceptual speed. All measures were converted to z-scores, then the two paper-and-pencil perceptual speed measures were averaged to form a composite perceptual speed score and the recall accuracy scores on the two lists were averaged to form a composite memory score. The age-related variance in the recall memory score was .162 , but it was reduced about $83 \%$, to .026 , when perceptual speed was controlled.

This same pattern of attenuated age-related effects after control of speed has been observed in a variety of other memory measures in a number of studies (e.g., Hultsch, Hertzog, \& Dixon, 1990; Salthouse, 1994, 1995; Salthouse \& Babcock, 1991). Furthermore, Salthouse’s (1996) results have been supported by a number of other studies in which a number of memory tasks were used, such as free recall (e.g., Bryan \& Luszcz, 1996; Huang, 1996), serial recall (e.g., Salthouse \& Coon, 1993), cued recall, and spatial memory (e.g., Park et al., 1996). Thus, individual-differences studies, especially with regression techniques, have very consistently 
shown that a speed construct mediates age differences in memory (see Salthouse, 1996b, for a detailed review of processing-speed theory).

\section{$\underline{\text { Working Memory }}$}

Working memory can be viewed as the amount of cognitive resource available to store some information while at the same time processing incoming or recently accessed information. Working memory is distinguished from other related memory systems primarily because of its importance in a great variety of cognitive tasks (Baddeley, 1986; Salthouse, 1990, 1991). For example, Charness (1985) found that working memory is critical in mental multiplication. The limitations of working memory become apparent when one tries to multiply two-digit numbers mentally, using neither paper and pencil nor any calculating devices. The difficulty in such problems is not attributable to any particular step in the procedure; it occurs because the combined storage and processing requirements exceed the capacity of working memory.

Several studies showed that age-related differences in mental arithmetic are associated with limitations of working memory. Wright (1981) found that younger and older adults did not differ when arithmetic problems were presented visually, but that older adults made more errors than younger adults when one or both numbers in the problem were presented auditorily, which presumably required more working memory capacity. Foos (1989) presented three problems involving pairs of two-digit numbers, and ensured working memory involvement by requiring all three problems to be solved before reporting the solutions to any of them. Older adults were generally less accurate than younger adults, especially on the middle problem in the series. Foos interpreted the age by serial position interaction as indicating a loss of information from working 
memory.

A number of studies suggested that working memory mediates the age-related variance in a number of other cognitive tasks, such as language comprehension and problem solving (e.g., Charness, 1985; Cohen, 1979; Light \& Anderson, 1985; Salthouse, 1991; Salthouse \& Skovronek, 1992; Stine \& Wingfield, 1987). For example, Stine and Wingfield (1987) reported that working memory accounted for $44 \%$ of the age-related variance on a speech comprehension task. A series of studies by Welford showed that working memory capacity, particularly the limitation of holding information while performing other cognitive operations, is a major factor responsible for age differences in perceptual-motor skills (Welford, 1958), learning and problem solving (Welford, 1958), abstraction (Welford, 1962), and thinking and fluid intelligence (Welford, 1980).

Because working memory is a complex concept that includes storage, processing, and coordination operations and three components (phonological loop, visual-spatial sketchpad, and central executive), researchers have debated on which aspects of working memory are more important for age differences in cognition. This debate also invoked the question on how working memory should be assessed. Some researchers believed that storage is more importance for age differences in working memory. Parkinson and his colleagues reported that many age differences in more complex memory tasks are eliminated when participants are matched on digit span. This finding was replicated by Puckett and Lawson (1989). Some researchers argued that the limitation in storage capacity of working memory was caused by the intrusion of irrelevant information, which was hypothesized to be the major cause of age differences in working memory (Hasher \& Zacks, 1988; Zacks \& Hasher, 1988). Other researchers, however, believed 
that reduction in the efficiency of processing is the major cause of age differences in working memory (Baddeley, 1986; Craik, 1977; Craik \& Rabinowitz, 1984; Gick et al., 1988; Morris et al, 1988). In addition, a number of studies have shown that age differences in working memory are largely attributable to age-related deficits in coordinating information (Kirchner, 1958; Talland, 1968; Taub, 1968; Welford, 1958). How the aging process influences the three components of working memory is still under investigation. However, one suggestion is that the central executive component of working memory is more impaired in the elderly. For example, Fisk and Warr (1996) found that only a small age difference in the phonological loop as measured by word span, but a large age difference in central executive functioning as measured by random-letter generation. Controlling for age differences in central executive functioning removed over $50 \%$ of the age-related variance in working memory, which was measured by the Computation-span and the Reading-span tests.

Because the relative importance of aspects of working memory is still under investigation, many tests have been developed to measure the core concept of working memory, which is holding information while processing other information at the same time. Among these measures, the Backward Digit-span, Listening-span, and Computation-span tests are most popular. In the Backward Digit-span test, the to-be-remembered digits not only have to be held while new members of the series are presented, but also have to be processed in a manner that permits their recall in reverse order. Research has shown some success using this measure (Salthouse, 1988c). The Listening-span test was first developed by Daneman and Carpenter (1980). In this test, the participants are asked either to read or listen to a series of sentences with the intent to recall in serial order the last word from each sentence. A person's listening span is 
determined by the longest number of sentences spanned without an error. This test requires both passive storing and active processing. Research has shown that when working memory is assessed with the Listening-span test, younger and older adults are significantly different (Light \& Anderson, 1985). Furthermore, age differences in listening span are related to the scores in memory tasks (e.g., retention of stories and recalling short prose passages) (Pratt, Boyes, Robins, \& Manchester, 1989; Stine \& Wingfield, 1987). The Computation-span test was introduced by Salthouse and his colleagues (Babcock \& Salthouse, 1990; Salthouse \& Babcock, 1991; Salthouse \& Mitchell, 1989). In the Computation-span test, participants are required to solve a series of simple arithmetic questions that are presented auditorially. They have to solve problems in a short period of time and remember the last digit of problems in their original order. A person's working memory capacity is determined by the number of problems solved and the number of digits remembered. A number of studies have shown that the Computation-span scores account for age-related differences in memory (e.g., Huang, 1996; Fieske \& Park, 1993; Park et al., 1996). Regardless of different measurements used to assess working memory, research has shown the importance of working memory as a processing resource in cognitive aging.

Experimental data. A few researchers used the experimental approach to assess the importance of working memory in age-related cognitive functions. Light and Capps (1986) found that younger and older adults were equally good at identifying the antecedants of pronouns when memory load was low (i.e., when no material intervened between a sentence containing a pronoun and a sentence containing its antecedent), but they found an age-related difference when two sentences intervened. Light and Albertson (1988) found that shifting the topic of background 
information had a more deleterious effect on ability to detect anomalies in short prose passages in older adults than in younger adults; they attributed this difference to reduced ability to retain prior relevant information. Using within-context assessments of working-memory capacity, Salthouse and his colleagues have manipulated complexity by varying the number of identical mental operations that must be carried out within a task. For example, Salthouse and his colleagues asked research participants to complete tasks in which several relevant premises had to be integrated in verbal reasoning (Salthouse et al., 1989), tasks in which the number of folds in a piece of paper had to be kept track of so that after a hole was punched the appearance of the unfolded paper could be described (Salthouse et al., 1989), and tasks in which several frames had to be integrated in a spatial visualization task (Salthouse, 1987; Salthouse \& Mitchell, 1989). Older adults were generally more adversely affected by increasing complexity, suggesting a reduced working-memory capacity.

A dual task methodology has been used to assess the relation between working memory and age in cognitive tasks, including free recall. An early study by Baddeley, Lewis, Eldridge, and Thomson (1984) showed that when working memory was suppressed by concurrent speech, such as reciting the single word "the" while studying a list of words, recall performance was reduced dramatically. Huang (1996) used the same method testing two groups of young adults and a group of older adults on a 4-trial free-recall task. One group of young adults recited a word aloud to suppress working memory while encoding 32 unrelated words on each trial. The other group of younger adults and the older adults were given the memory task in the standard way, without suppression. The younger adults in the standard condition outperformed the suppression group and the older adults in recall performance and the suppression group of young adults was 
equivalent to the old.

Morris, Craik, and Gick (1990) used a memory preload method developed by Baddeley and Hitch (1974). In Experiment 1, younger and older adults had to hold two, three, four, and five unrelated words in mind while judging whether a sentence was true or false. The words to be remembered were given first, and then the sentence was presented; participants were asked to verify the sentence as rapidly as possible and then to recall the unrelated words in their original order. An age-related decrement was found in the serial recall of the words, and this decrement was larger with longer word lists. In Experiment 2, this result was replicated with longer lists of words and free recall rather than serial recall. However, processing speed and working memory were not manipulated at the same time in these experiments. Thus, no information is available on how these two major resources interact in memory performance. The present study includes both factors in order to determine how they interact in age differences in free recall.

Individual-differences data. Individual-differences research on working memory in age differences in memory has revealed that working memory significantly correlates with age differences in memory for text and words (Hultsch, Hertzog, \& Dixon, 1990). Frieske and Park (1993) found that working memory plays a more important role in accounting for age differences in recognition of unorganized compared with organized pictures. Bryan and Luszcz (1996) found that when speed of processing measured by the Digit Symbol Substitution Test was controlled, working memory was no longer a significant factor accounting for age-related variance in free recall. However, they used the Backward Word-span test as the measure for working memory. In a study by Park et al. (1996), working memory was measured by the Backward Digit-span, Reading-span, and Computation-span tests. A structural equation model was used to assess the 
contributions by working memory and speed. They found that working memory was important for free recall and cued recall even after speed was controlled, but not for spatial memory. They suggested that although speed is a central construct in explaining age-related variance in memory performance, working memory is a useful construct, particularly for more effortful types of memory such as free recall. They also suggested that speed operates through working memory. These results are consistent with a prediction made earlier by Mayr and Kliegl (1993), Kliegl, Mayr, and Krampe (1994), Nettelbeck and Rabbitt (1992), and Rabbitt (1993). These researchers suggested that a simple speed model of age differences in cognitive functioning might not be adequent when tasks are more demanding of resources. Furthermore, Rabbitt (1993) and Nettelbeck and Rabbitt (1992) presented evidence that substantial age-related variance in memory functioning is not accounted for by speed. Despite the recent success in assessing the contribution of working memory to memory, little information is available regarding the interaction between working memory and speed, and between these processing resources and other factors such as cautiousness and memory self-efficacy. The present study included all these factors to provide a clearer description of how these factors mediate age differences in free recall.

\section{Cautiousness}

Cautiousness is commonly reported to increase with increasing age (Botwinick, 1966; Wallach \& Kogan, 1961). Schaie and Willis (1991) described cautiousness as a way that older adults defend themselves against the anxieties of old age. As people grow old, they tend to become more careful and conservative in their cognitive and perceptual activities. They often trade off speed of response to increase accuracy (Botwinick, 1978; Salthouse, 1979, 1982). They 
often try to avoid mistakes more than to succeed at a task, which results in omission errors in their responses. For example, older adults tended to make no response at all to a question in an intelligence test (Zelinski, Schaie, \& Gribbin, 1977). In a perceptual discrimination task, older subjects could respond as fast as younger subjects, but preferred to gather more information from the display before responding (Botwinick, Brinley, \& Robbin, 1958). Older adults' cautiousness not only is reflected in cognitive tasks, but also is exhibited when they are asked to respond to questions about their attitudes and opinions (Gergen \& Back, 1966). Research has shown that the tendency of older adults to select less risky situations seems to hold only when the payoff is relatively limited (Okun \& DiVesta, 1976). When a substantial reward is offered, older adults are as likely as younger adults to prefer the riskier situation (Okun \& Elias, 1977). The increased cautiousness of older adults often results in an exaggerated decline in intelligence, learning, memory, and perception (e.g., Rees \& Botwinick, 1971). Therefore, age differences in many cognitive and perceptual tasks reflect not only a decline in the ability being tested but also increased cautiousness of older adults.

Signal Detection Theory has been used to study the effects of cautiousness in memory. Wickelgren and Norman (1966) and Banks (1970) suggested that memory in general and recognition memory in particular could be viewed as a signal detection task. In the recognition task, a "yes" response will depend both on memory trace strength or "sensitivity" (d') and on a response criterion (b). A pilot study by Craik (1969) showed that when a six-point scale was used, older adults tended to use a more stringent criterion than young adults, but both age groups had the same sensitivity. Gordon and Clark (1974a) studied age differences in sensitivity and response bias on a prose recognition task. A paragraph was read aloud to each participant and a 
recognition test consisting of 32 true-false questions was given after a delay. A true-false question is analogous to the yes-no design in Signal Detection Theory. Older adults had a lower recognition performance, but no age difference on response criterion was found. Gordon and Clark (1974b) also studied age differences in word and nonsense syllable recognition memory. Younger and older adults were given two-trial recognition memory tests for separate lists of 60 words and 60 nonsense syllables. The sensitivity measure d' in both age group indicated that older adults were less sensitive than the young for both words and nonsense syllables. The older adults set a higher criterion than the young adults for words, but set a lower criterion than the young for nonsense syllables in the first trial and increased to the same level as the young in the second trial.

Harkins, Chapman, and Eisdorfer (1979) used a six-point rating scale to study age difference in recognition memory for 60 words. After the presentation, 120 words, 60 of which were "old" and 60 "new," were given to each participant to evaluate. Harkins et al. found that older adults had lower sensitivity than the young. With regard to response bias, the older adults used the "definitely old" category significantly more often than the young, but they used the “definitely new" and "probably new" categories significantly less often than the young, indicating that the young adults were less conservative than the old in using the latter categories. An overall analysis revealed that older adults adopted a more lax response criterion than the young, which resulted in a higher correct recognition rate.

Le Breck and Baron (1987) studied age differences in practice effects in recognition memory. Younger and older women were asked to identify new and old items. The items were letter-number combinations (e.g., A42G). Training interval and presentation mode (auditory vs. 
visual) were within-subjects factors. Performance improved with increased training interval for both young and old women. An age-related decline in sensitivity rather than criterion was found. For both groups, use of a conservative criterion was greater when the intervals were longer and when the task was visual. Once again, no age difference in response criterion was found, suggesting that age differences in response criterion are not a general phenomenon.

The results summarized above show that older adults use the same response criterion as the younger adults in some tasks, but in other tasks use a more conservative or a less conservative criterion than younger adults. Older adults also have the same sensitivity as younger adults in some tasks, but in most tasks are less sensitive than the young.

Monetary reward and incentive were also used to test the effects of cautiousness in age differences in cognition. In associative learning tasks, older participants were offered a small monetary reward for each correct response. Each incorrect response was also rewarded, although at a slightly lower value. Only the absence of a response received no reward. In this situation, the older adults significantly reduced their omission errors. This finding suggests that older adults could do better on many tests of learning merely by taking a few more chances, guessing at least when they have some idea of the answer (Birkhill \& Schaie, 1975; Leech \& Witte, 1971).

However, very little research on cautiousness in aging has dealt with factors such as processing speed and working memory, and very little research on processing speed and working memory in aging has dealt with cautiousness of the elderly. In the present study, cautiousness was manipulated along with the manipulation of processing speed and working memory to provide evidence on age differences in memory performance. 
Memory Self-efficacy

According to common sense, our performance is influenced by our sense of competence and confidence in a given domain. This idea is captured by the self-efficacy concept, which Bandura (1977) introduced in social learning terms. According to Bandura (1986, p. 391), selfefficacy is defined as "people's judgments of their capabilities to organize and execute courses of action required to attain designated types of performances." Bandura (1977) also emphasized that a person's self-efficacy is not a global self-evaluation, but is tied to particular task demands and characteristics of a given situation. Self-efficacy is a dynamic entity and it is sensitive to changes in task demands, situational determinants, social context, and individual development. Research has shown that perceptions of self-efficacy may increase, decrease, or remain the same as development progresses and the individual moves through various social contexts (Bandura, 1981, 1989, 1990). A number of studies have suggested that older adults have a lower selfefficacy than the young in many domains (Berry, West, \& Dennehey, 1989; Hertzog, Dixon, \& Hultsch, 1990; Lachman \& Leff, 1989). Langer and Avorn (1982) hypothesized that three factors could reduce a person's self-efficacy: (1) Being assigned a label that denotes inferiority and incompetence, (2) being denied an opportunity to participate in a task that one formerly participated in, and (3) receiving excessive help from someone else. (See Bandura, 1977, and Berry and West, 1993, for detailed review of self-efficacy theory and cognitive self-efficacy across the life span, respectively.)

Memory self-efficacy is roughly defined as a person's belief about his/her own ability to remember (Berry et al., 1989; Dixon, 1989; Hertzog, Hultsch, \& Dixon, 1989). Research on memory self-efficacy in adulthood and aging grew out of age-related studies of metamemory 
(e.g., Perlmutter, 1978) and memory complaints and concerns in the elderly (e.g., Scogin, Storandt, \& Lott, 1985). Older adults clearly have a poorer sense of self-efficacy than the young when self-efficacy is measured by several different types of memory self-efficacy tests, including the Metamemory in Adulthood questionnaire (Cavanaugh \& Poon, 1989; Hertzog et al., 1990; Hultsch, Hertzog, Dixon, Davidson, 1988), single-item self-efficacy predictions for digit and word recall (Hertzog, 1992), and multilevel task-specific measures of self-efficacy strength and level (e.g., Berry et al., 1989). Regardless of the measure used, self-efficacy is highly correlated with memory performance (Berry, 1987; Berry et al., 1989; Dixon \& Hultsch, 1983a, 1983b; Hertzog, et al., 1990; Lachman, Steinberg, \& Trotter, 1987; Rebok \& Jelalian, 1984; West \& Bramblett, 1990), and the correlation does not vary with age (Hertzog, 1992; Rebok \& Balcerak, 1989). Berry and West (1993) argued that self-efficacy is derived from previous memory performance and therefore is correlated with present memory performance because previous and present memory performance is related, and that self-efficacy as such also has a direct effect on present memory performance. In the present study, self-efficacy was assessed using the Memory Self-Efficacy Questionnaire (Berry et al., 1989). The intent was to replicate previous findings regarding self-efficacy and memory in aging. 
Statement of the Problem

The preceding review indicates a strong research interest in the effects of processing resource on aging cognition in general and aging memory in particular. However, studies focused on processing resources tend to neglect variables such as cautiousness and self-efficacy, in the psychosocial domain of aging. A recently published handbook of aging (Birren \& Shaie, 1995) contains no entry on cautiousness and memory self-efficacy. Also, a review of the literature shows that most of the research on cautiousness was done in the 1970s. Only a few studies have been done on memory self-efficacy in the 1990s. Reasons for the neglect of cautiousness and memory self-efficacy may be the difficulties of investigation, editors' preferences, and conflicting data. Nevertheless, this tendency is inimical to complete understanding of aging processes. In this study, cautiousness and memory self-efficacy were investigated. Cautiousness was directly manipulated by monetary reinforcement in younger adults along with processing resources to shed light on how cautiousness interacts with resources in age difference in free recall. Memory self-efficacy was measured to assess its contribution to age differences in free recall. It was expected that effects of cautiousness and memory self-efficacy on memory performance could be identified using a combined experimental and correlational approach.

Most of the studies that were designed to assess the contribution of processing speed and working memory to age differences in memory performance are correlational. Correlational studies, especially when advanced statistical techniques are employed, can provide potential explanations of aging memory, but because they cannot specify the direction of the influences among the variables, they are inferior to experimental studies. However, in most of the experimental studies, only one of the constructs was manipulated (e.g., Bryan \& Luszcz, 1996; 
Huang, 1996). Thus, the causal relation of processing resources to age differences in memory performance needed further study. Furthermore, the studies using correlational methods have generated conflicting data. For example, Bryan and Luszcz (1996) found that when processing speed was controlled, working memory did not account for significant age-related variance in free recall. However, Huang (1996) and Park et al. (1996) found that working memory still accounted for significant age-related variance after processing speed was controlled. Thus, the interaction between processing speed and working memory needed further study. The main goal of the present study was to use both experimental and correlational approaches to bring convergent evidence on how speed and working memory influence age differences in free recall and to provide evidence on how processing speed and working memory interact with each other.

This study used a simulation strategy and a repeated-measures Latin-square design in the experimental manipulations. The simulation strategy has two major strengths (Baltes, Reese, \& Nesselroade, 1988). One is its power to provide causal explanations of age differences in cognition and development. The other is its emphasis on theory construction, because any simulation has to be based on theory. The successes and failures of a particular simulation provide not only evidence on the effectiveness of the simulation, but also tests of the theory that the simulation is based on. The Latin-square design not only allows researchers to counterbalance treatments across procedural variables, but also reduces the number of treatment combinations given to each participant. These features of the Latin-square design are very appealing when multiple variables are included in a study, because in an orthogonal design the numbers of participants and treatment conditions grow exponentially. The Latin-square design can reduce the 
number of participants while not sacrificing power (see Reese, 1997, for a detailed review on Latin-square designs).

In the present study, the simulation of speed was implemented by the number of syllables of the to-be-remembered words. This method was used by Salthouse (1980) and found effective in related studies by Baddeley (1986). The simulation of working memory capacity was implemented by a dual-task technique, in which the participants had to perform two tasks at the same time. The primary task was free recall and the secondary task was concurrent digit load. In the concurrent digit-load task, the participants had to pay attention to a series of strings of digits and recall the digits in each string in their original order. Baddeley et al. (1983) found that the concurrent digit load reduces the free-recall performance of younger adults to a greater extent than digit preload, even though the two methods produced similar serial position functions.

Cautiousness was simulated in younger adults by using monetary incentives. Using monetary incentives has been shown to be effective in manipulating participants' cautiousness. I hypothesized that younger adults whose speed, working memory, and cautiousness level were experimentally manipulated could behave like older adults whose speed, working memory, and cautiousness reflected aging.

An individual-differences approach was also taken to investigate the relations of processing speed, working memory, and memory self-efficacy to free recall. A number of researchers have used this approach and found that speed, but not working memory, is critical for age differences in free recall (e.g., Bryan \& Luszcz, 1996; Salthouse, 1996). However, some researchers have found that working memory cannot be neglected in aging memory, especially when memory requires more effortful processes, as in free recall (e.g., Huang, 1996; Park et al., 
1996). The discrepancies among the studies have been hypothesized to reflect the measures chosen to measure speed and working memory. When working memory was measured by digit span, negative results were generally obtained, and when working memory was measured by Computation-span and Listening-span tests, the results generally indicated effects of working memory on memory. In the present study, Backward Digit-span, Forward Digit-span, and Computation-span tests were used to clarify the effects of measurement on the correlation between working memory and aging memory.

Memory self-efficacy was assessed for two purposes. First, I wanted to use memory selfefficacy as a control variable, by confirming that it is correlated with age difference in free recall. Second, the memory self-efficacy test used allows separation of confidence ratings from estimates of skill level. In the present study, these variables were analyzed to test the hypothesis that old adults may have a lower confidence level than the young regardless of their skill level. I also used memory self-efficacy as a covariate in analysis of free-recall performance to assess relations of this individual-differences variable to the manipulated variables.

In summary, a combined experimental and individual-differences approach was taken to study the effects of processing speed, working memory, cautiousness, and memory self-efficacy on age-related differences in free recall. Manipulating speed, working memory, and cautiousness permitted finding the interactions among these variables and testing the relative importance of these variables in aging memory. Correlational analysis methods were used to test the mediating roles of speed, working memory, and memory self-efficacy on free recall. Table 1 shows the predictions in this study. 
Table 1. Predications in the present study

Number Prediction

1

The effects of speed, working memory, and cautiousness will be additive and no interaction of these variable will be found in the younger adults.

Word-length effect will be obtained in both younger and older adults. Manipulation of speed will reduce age difference in free recall. There will be a significant decrease in recall in dual task condition, which reduces age difference in free recall.

High cautiousness will reduce the number of words recalled, which reduces age differences in free recall.

The effect of Memory Self-efficacy will be moderate compared with the effects of speed, working memory, and cautiousness.

The Digit Symbol Substitution Test and Finding A's test will be significantly correlated with age, recall, and between each other.

The Forward Digit-span test, the Backward Digit-span test, and the Computation Span test will significantly correlated with age, recall, and among themselves. Strength Level will not. Memory Self Efficacy Level will significantly correlated with recall. Both speed measures accounted for significant variance and accounted for the effect of age. More age-related variance in recall will be accounted for by the speed and working memory than the Memory Self-efficacy. controlled. 
Method

\section{$\underline{\text { Participants }}$}

Eighty college students ( 29 male and 51 female, mean age $=23$ years, $\underline{\mathrm{SD}}=1.60$ years) and 40 older adults (15 male and 25 female, mean age $=75$ years, $\underline{\mathrm{SD}}=6.47$ years $)$ were recruited for the study. Two other older adults were excluded because they had taken memorysensitive drugs, such as Prinivil, Lopressor, and Atenol. Each participant was paid \$5 for his/her participation, plus a variable monetary incentive based on his or her assigned cautiousnessmanipulation condition.

Table 2 identifies demographic characteristics of the sample. Educational level was measured by years of formal education; health was self-rated on a seven-point scale $(1=$ very good, 7 = very poor).

\section{Experimental Manipulations}

For the younger adults, processing speed, working memory, and cautiousness were manipulated to simulate aging effects. The manipulation of processing speed and cautiousness were between subjects; the manipulation of working memory was within-subjects. Consistent with Salthouse (1980), processing speed was manipulated by the number of syllables in the tobe-remembered words (1-syllable and 3-syllable). Because the duration of pronouncing words with 3 syllables is longer than pronouncing words with 1 syllables, using 3-syllable words simulates slower processing speed in the elderly. Working memory capacity was manipulated by concurrent digit load. In the dual-task condition, the participant was asked to listen to a series of strings of 6 digits and recall the digits in their original order, while he or she was trying to 
remember the to-be-remembered words presented on a computer screen at the same time. In the control condition, the participant was given the word-memory task without the concurrent digit load. Because trying to remember digits and words at the same time takes more working memory capacity, the condition using concurrent digit load simulates reduced working memory capacity in the elderly. Cautiousness was manipulated by monetary incentive and instructions. Participants in a low cautiousness condition were told they would receive $\$ 5$ for participation and $\$ 0.40$ for each correctly recalled word. They were also told that the best strategy to increase their earnings was guessing and reporting any words that came to mind. Participants in a high cautiousness condition were told they would receive $\$ 5$ for their participation and $\$ 0.40$ for each correctly recalled word, but they would be penalized $\$ 0.20$ for each incorrect word they reported. They were told that the best strategy was avoiding errors and reporting only words they were very sure were in the list.

The older adults were divided into two groups to provide data to check the simulations used with the younger adults. One group was tested with 1-syllable words and the other group tested with 3-syllable words. Both groups were tested only in the control task with the low cautiousness condition. 
Table 2

Means (and standard deviations) of demographic characteristic of the younger and older adults (n $=120$ )

\begin{tabular}{|c|c|c|c|c|c|c|}
\hline \multirow[b]{3}{*}{ Variable } & \multicolumn{4}{|c|}{ Young } & \multicolumn{2}{|c|}{ Old } \\
\hline & \multicolumn{2}{|c|}{ Low cautiousness } & \multicolumn{2}{|c|}{ High cautiousnes } & \multicolumn{2}{|c|}{ Low cautiousness } \\
\hline & 1 -syllable & 3-syllable & $1-$ syllable & 3 -syllable & $1-\operatorname{syllable}$ & 3-syllable \\
\hline Age (in years) & $\begin{array}{l}22.30 \\
(1.81)\end{array}$ & $\begin{array}{l}21.75 \\
(1.25)\end{array}$ & $\begin{array}{l}21.60 \\
(1.23)\end{array}$ & $\begin{array}{l}21.75 \\
(1.25)\end{array}$ & $\begin{array}{l}72.20 \\
(5.82)\end{array}$ & $\begin{array}{l}77.80 \\
(5.96)\end{array}$ \\
\hline Number of males & 6 & 8 & 7 & 8 & 7 & 8 \\
\hline Number of females & 14 & 12 & 13 & 12 & 13 & 12 \\
\hline Years of education & $\begin{array}{l}14.70 \\
(1.63)\end{array}$ & $\begin{array}{l}14.00 \\
(1.12)\end{array}$ & $\begin{array}{l}14.30 \\
(1.26)\end{array}$ & $\begin{array}{l}14.25 \\
(1.71)\end{array}$ & $\begin{array}{l}16.50 \\
(4.68)\end{array}$ & $\begin{array}{l}15.55 \\
(3.33)\end{array}$ \\
\hline Subjective health & $\begin{array}{c}2.25 \\
(1.21)\end{array}$ & $\begin{array}{c}1.90 \\
(1.07)\end{array}$ & $\begin{array}{c}2.05 \\
(1.00)\end{array}$ & $\begin{array}{c}2.25 \\
(0.97)\end{array}$ & $\begin{array}{c}1.90 \\
(0.85)\end{array}$ & $\begin{array}{c}1.70 \\
(1.26)\end{array}$ \\
\hline
\end{tabular}




\section{$\underline{\text { Individual-Differences Measures }}$}

A number of individual-differences measures were used to assess participants' processing speed, working memory, and memory self-efficacy. Processing speed was assessed with the WAIS-R Digit Symbol Substitution Test (Wechsler, 1981) and the Finding A's test (Eckstrom et al. 1976). Working memory was assessed by Forward and Backward Digit-span tests (Wechsler, 1981) and the Computation-span test (Salthouse \& Babcock, 1990). In the Computation-span test, the participants were asked to solve simple arithmetic problems while simultaneously attempting to remember the last digit in each problem. After they solved the arithmetic problems, they were instructed to recall the last digits in the original order of presentation by writing them down on a separate page. An error was counted if any question was answered incorrectly or if any digit was not recalled in its original serial position. Three trials were given at each span length from 1 to 6 . The test was stopped when errors were made on three consecutive trials with a given span length. Memory self-efficacy was assessed by the Memory Self-efficacy Questionnaire (Berry et al., 1989). All tests have high reliability and validity and have been used extensively in assessing perceptual speed, working memory, and memory self-efficacy in adulthood and aging research.

\section{$\underline{\text { Materials }}$}

Memory was assessed by free recall of lists of words. Two 16-item lists of 1-syllable and two 16-item lists of 3-syllable words with high frequency were selected from the Paivio, Yuille, and Madigan (1968) norms. They are listed in Appendix A. For each word length, assignment to lists was random. For the dual-task condition, the 6-digit strings were constructed by assigning 
the digits from 0 to 9 at random order.

\section{$\underline{\text { Design }}$}

The design for the young adults was 2 (sex) by 2 (processing speed: 1- vs. 3-syllable words) by 2 (cautiousness) by 2 (working memory: dual-task vs. control task) mixed design with the last variable within-subjects. The order of the two within-subjects conditions was counterbalanced with the Latin-square arrangement, shown in Table 3. Memory performance was assessed by free recall. The young adults were divided at random within sexes into four groups, 1-syllable low cautiousness, 1-syllable high cautiousness, 3-syllable low cautiousness, and 3syllable high cautiousness. The participants in the 1-syllable groups were given the dual-task first and then the control task. The participants in the 3-syllable groups were given the control task first and then the dual task. In this design, the word- length simulation of processing speed is confounded with any interaction between the working memory manipulation (dual vs. control task) and task order and with any interaction between the working memory manipulation and word list (A or B). Word list was also confounded with task order - all participants received List A of 1- or 3-syllable words first and List B second. These and other confoundings are illustrated in Appendix B. The confoundings involved in this design is not expected to have any influence of the results of experimental manipulations in that testing order and word lists would have nonsignificant effects on free recall performance.

The older adults were given a study-test trial with 1-syllable/3-syllable List A and then a study-test trial with 1-syllable/3-syllable List B. The performance of the older adults provided control performance for the experimental simulation checks. 
$\underline{\text { Procedure }}$

Participants were tested individually in a quiet laboratory. After they read and signed the consent form, they were given the free recall tasks with the appropriate working memory and cautiousness instructions. They were asked to remember the words, which were presented as lowercase white words on a black background in the center of a computer monitor screen. The words were $1 \mathrm{~cm}$ in height, and ranged from 2 to $5 \mathrm{~cm}$ in width; the presentation duration and inter-item interval were 1.5 seconds. Participants were seated approximately 35 to $40 \mathrm{~cm}$ from the screen. Immediately after studying each list, participants were asked to write down the words they remembered. In the dual-task condition, the participants recalled aloud the digits in their original order after each 6-digit string was presented. The digits were recorded on tapes and presented auditorially at a pace of 1 digit per second with about 1 second between digits. Ten seconds were allowed after each string for recall. The participants were told to stop recalling digits once they saw a "please recall" sign on the screen; this sign indicated that they should immediately recall the words by writing them down. The older adults were given their recall tasks twice with sequence of List A and List B. One group of older adults were given 1-syllable words and another group were given 3-syllable words.

After the free recall task, participants were given the Memory Self-efficacy Questionnaire, the Finding A's test, the Digit Symbol Substitution Test, the Forward Digit-span test, the Backward Digit-span test, the Computation-span test, and a demographic questionnaire in that order. The demographic questionnaire is presented in Appendix C. 
Table 3

The within-subjects Latin-square design used with the young adults

\begin{tabular}{lll}
\hline & \multicolumn{2}{c}{ Working memory simulation } \\
\cline { 2 - 3 } Order & Dual task & Control task \\
\hline First task & List A of 1-syllable & List A of 3-syllable \\
& words (Subgroup 1) & words (Subgroup 2) \\
Second task & List B of 3-syllable & List B of 1-syllable \\
& words (Subgroup 2) & words (Subgroup 1) \\
\hline
\end{tabular}


Results

The 5\% level of significance was used for all analyses. Fisher's (1935) least significant difference test (LSD) was chosen to perform follow-up analyses. The rationale for using LSD is that LSD is the most powerful test for detecting simple effect, after the significant interaction was found (Reese, 1970). Task order and list were confounded with the speed and working memory manipulations, therefore, these two variables were not analyzable in the present study. However, they were nuisance variables (Keppel, 1991) in the present study. Furthermore, analyses of the list effects using the sample of older adults did not reveal any significant differences between Lists A and B. All analyses of variance included sex and serial position as sources of variance. Serial position was defined as words 1-4, 5-8, 9-12, and 13-16.

\section{Experimental Data}

\section{$\underline{\text { Simulation Checks }}$}

The mean accuracy of concurrent digit recall by the young adults in the dual task condition was $93 \%(\mathrm{SD}=0.08)$. Analysis of variance revealed no significant differences among the young-adult groups in the accuracy of digit recall, $\underline{\mathrm{F}}(3,76)=1.31, \underline{\mathrm{MSE}}=0.01, \underline{\mathrm{p}}>.5$. Thus, the participants took the digit-recall task seriously, and it therefore presumably increased the load on working memory.

Table 4 summarized the word recall performance of the younger and older adults in all conditions, and Table 5 summarized the analyses of variance used for the simulation checks described in the following paragraphs. Preliminary analyses revealed that there was no interactions among speed, working memory, and cautiousness, which confirmed the prediction 1. 
Therefore, the simulation check was conducted on each simulation individually.

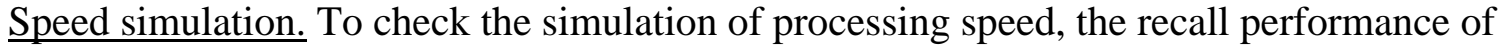
the younger adults in the 3-syllable low cautiousness control task condition in the first task was compared with that of the older adults in the 1-syllable low cautiousness control task condition in the first list. The main effect of age, the age by sex, the age by serial position, and the sex by serial position interactions were not significant. Thus, the simulation was effective in all serial positions. Recall by the younger adults was reduced to the level of recall by the older adults. These results confirmed the prediction 2 and 3 .

Working memory simulation. To check the simulation of working memory, the recall performance of the younger adults in the 1-syllable low cautiousness dual task condition in the first task was compared with that of the older adults in the 1-syllable low cautiousness control task condition in the first list. The main effect of age was not significant, but the age by sex and age by serial position interactions were significant. Follow-up analyses indicated that, for the younger adults, more words in position 1 and 4 were recalled than position 2 and 3 . The number of words recalled in position 2 and 3 did not differ from each other. The same results were also obtained in the older adults. The younger adults recalled more words than the older adults did on the third position. Thus, the simulation was effective only in the position 1,2 , and 4 . This result confirmed the prediction 4. 
Table 4

Means (and standard deviations) of the numbers of words recalled by the younger and older adults ( $\mathrm{n}=120$ )

\begin{tabular}{|c|c|c|c|c|c|c|}
\hline & \multicolumn{4}{|c|}{ Young } & \multicolumn{2}{|c|}{ Old } \\
\hline & \multicolumn{2}{|c|}{ Low cautiousness } & \multicolumn{2}{|c|}{ High cautiousness } & \multicolumn{2}{|c|}{ Low cautiousness } \\
\hline & Control & Dual-task & Control & Dual-task & List 1 & List 2 \\
\hline Syllable & M & M & M & M & M & M \\
\hline \multicolumn{7}{|c|}{ Serial position 1} \\
\hline $\begin{array}{l}\text { 1-syllable words } \\
\text { 3-syllable words }\end{array}$ & $\begin{array}{c}2.40 \\
(0.68) \\
2.20 \\
(0.52)\end{array}$ & $\begin{array}{c}1.80 \\
(0.70) \\
1.65 \\
(0.95)\end{array}$ & $\begin{array}{c}2.05 \\
(0.94) \\
1.35 \\
(1.04)\end{array}$ & $\begin{array}{c}1.40 \\
(0.48) \\
1.85 \\
(0.81)\end{array}$ & $\begin{array}{c}1.85 \\
(0.67) \\
1.90 \\
(0.91)\end{array}$ & $\begin{array}{c}1.95 \\
(0.76) \\
1.80 \\
(0.89)\end{array}$ \\
\hline $\begin{array}{l}\text { 1-syllable words } \\
3 \text {-syllable words }\end{array}$ & $\begin{array}{c}0.80 \\
(1.01) \\
0.75 \\
(0.83)\end{array}$ & $\begin{array}{c}0.60 \\
(0.60) \\
0.55 \\
(0.60)\end{array}$ & $\begin{array}{c}0.85{ }^{S} \\
(0.88) \\
1.00 \\
(1.12)\end{array}$ & $\begin{array}{c}\text { osition } 2 \\
0.75 \\
(0.91) \\
0.50 \\
(0.76)\end{array}$ & $\begin{array}{c}0.55 \\
(0.69) \\
0.30 \\
(0.57)\end{array}$ & $\begin{array}{c}0.65 \\
(0.60) \\
0.40 \\
(0.60)\end{array}$ \\
\hline $\begin{array}{l}\text { 1-syllable words } \\
\text { 3-syllable words }\end{array}$ & $\begin{array}{c}0.80 \\
(0.95) \\
0.60 \\
(0.68)\end{array}$ & $\begin{array}{c}0.90 \\
(0.85) \\
0.70 \\
(0.80)\end{array}$ & $\begin{array}{c}1.40 \\
(0.88) \\
1.20 \\
(0.95)\end{array}$ & $\begin{array}{c}\text { oosition } 3 \\
0.80 \\
(0.89) \\
1.05 \\
(1.05)\end{array}$ & $\begin{array}{c}0.45 \\
(0.69) \\
0.35 \\
(0.67)\end{array}$ & $\begin{array}{c}0.50 \\
(0.66) \\
0.45 \\
(0.76)\end{array}$ \\
\hline $\begin{array}{l}\text { 1-syllable words } \\
3 \text {-syllable words }\end{array}$ & $\begin{array}{c}3.25 \\
(1.02) \\
2.70 \\
(0.60)\end{array}$ & $\begin{array}{c}2.65 \\
(0.94) \\
2.75 \\
(1.12)\end{array}$ & $\begin{array}{c}2.35 \\
(0.88) \\
2.00 \\
(0.86)\end{array}$ & $\begin{array}{c}\text { oosition } 4 \\
2.40 \\
(1.14) \\
1.93 \\
(1.22)\end{array}$ & $\begin{array}{c}2.60 \\
(0.88) \\
1.70 \\
(1.08)\end{array}$ & $\begin{array}{c}2.20 \\
(0.97) \\
1.35 \\
(1.04)\end{array}$ \\
\hline $\begin{array}{l}\text { 1-syllable words } \\
\text { 3-syllable words }\end{array}$ & $\begin{array}{c}7.25 \\
(1.83) \\
6.25 \\
(1.11)\end{array}$ & $\begin{array}{c}5.95 \\
(1.36) \\
5.65 \\
(2.16)\end{array}$ & $\begin{array}{c}6.65 \\
(2.03) \\
5.55 \\
(1.53)\end{array}$ & $\begin{array}{c}\text { sitions } \\
5.35 \\
(1.46) \\
5.33 \\
(1.93)\end{array}$ & $\begin{array}{c}5.45 \\
(1.89) \\
4.25 \\
(1.38)\end{array}$ & $\begin{array}{c}5.30 \\
(1.35) \\
4.00 \\
(1.52)\end{array}$ \\
\hline
\end{tabular}


Table 5

Summary of analysis of variance for the simulation checks ( $\mathrm{n}=$ 40)

F

\begin{tabular}{lrlll} 
Source of variance & df & Speed & Cautiousness & Working memory \\
\hline & & & & \\
Between-subjects & 39 & & & \\
Age (A) & 1 & 0.05 & 2.85 & 1.00 \\
Sex (S) & 1 & 0.11 & 0.08 & 0.39 \\
A x S & 1 & 1.69 & 1.56 & 0.25 \\
error (b) & 36 & & & \\
Within-subjects & 120 & & & \\
Position (P) & 3 & $68.30 * * *$ & $49.01^{* * *}$ & $0.77^{* * *}$ \\
A x P & 3 & 1.52 & $3.95^{*}$ & 0.86 \\
S x P & 3 & 0.44 & 0.38 & \\
A x S x P & 3 & 0.91 & 1.37 & \\
error (w) & 108 & & & \\
& & & &
\end{tabular}

Note. $\mathrm{MSE}=0.24$ for speed, 0.16 for cautiousness, and 0.12 for working memory.

$$
\begin{aligned}
* \mathrm{p} & <.05 \\
* * \mathrm{p} & <.01 \\
* * * \mathrm{p} & <.001
\end{aligned}
$$


Cautiousness simulation. To check the simulation of cautiousness, the recall performance of the younger adults in the 1-syllable high cautiousness control task condition in the second task was compared with that of the older adults in the 1-syllable low cautiousness control task condition in the second list. The main effect of age was significant, but again the age by serial position interaction was significant. Follow-up analyses indicated that the younger adults recalled significantly more words than the older adults only in the third position. Thus, the simulation was effective in position 1,2, and 4. This result confirmed prediction 5.

The age differences in the third serial position in both cautiousness and working memory manipulation suggested that older adults are more subjective to proactive interference than the younger adults. Alternatively, it might reflect larger working memory capacity in the younger adults, allowing them to include some items from Serial Position 3 in their "recency" recall.

Effects of manipulations. The effects of the simulation were analyzed among the younger adults using a 2 (sex) by 2 (speed) by 2 (working memory) by 2 (cautiousness) by 4 (serial position) analysis of variance with the last one variables as within-subject variables and with recall performance as the dependent variable. Predictions 2, 3, and 4 were confirmed by the significant main effects of speed, $\underline{\mathrm{F}}(1,72)=4.59, \underline{\mathrm{p}}<.05$, working memory, $\underline{\mathrm{F}}(1,72)=9.49$, $\underline{\mathrm{MSE}}=0.05, \underline{\mathrm{p}}<.01$, and cautiousness, $\underline{\mathrm{F}}(1,72)=4.27, \underline{\mathrm{MSE}}=0.05, \underline{\mathrm{p}}<.05$. There was a significant 5-way interaction of sex by speed by cautiousness by working memory by serial position, $\underline{\mathrm{F}}(3,216)=5.15, \underline{\mathrm{MSE}}=0.04, \underline{\mathrm{p}}<.01$. The follow-up tests started with a 2 (speed) by 2 (working memory) by 2 (cautiousness) by 4 (serial position) analysis of variance separately for male and female participants.

Male participants. For male participants, the significant effects were the main effects of 
serial position, $\underline{\mathrm{F}}(3,78)=2.09, \underline{\mathrm{MSE}}=0.07, \underline{\mathrm{p}}<.001$, and the serial position by cautiousness interaction, $\underline{\mathrm{F}}(3,78)=0.20, \underline{\mathrm{MSE}}=0.07, \underline{\mathrm{p}}<.05$. Table 6 shows the means and standard derivations of the recall performance in the male participants by cautiousness and serial positions.

Female participants. For female participants, the significant effects were the main effects of working memory, $\underline{\mathrm{F}}(1,46)=5.63, \underline{\mathrm{MSE}}=0.04, \underline{\mathrm{p}}<.5$, and serial position, $\underline{\mathrm{F}}(3,138)=79.03$, $\underline{\mathrm{MSE}}=0.05, \underline{\mathrm{p}}<.001$, and the cautiousness by syllable by working memory by serial position interaction, $\underline{\mathrm{F}}(3,138)=7.88, \underline{\mathrm{MSE}}=0.04, \underline{\mathrm{p}}<.001$. The 4-way interaction was analyzed by a 2 (cautiousness) by 2 (speed) by 2 (working memory) analysis of variance separately for each serial position. The only significant effects were the cautiousness by speed by working memory interactions in position $1, \underline{\mathrm{F}}(1,46)=7.12, \underline{\mathrm{MSE}}=0.03, \underline{\mathrm{p}}<.05$, position $3, \underline{\mathrm{F}}(1,46)=6.55$, $\underline{\mathrm{MSE}}=0.05, \underline{\mathrm{p}}<.05$, and position $4, \underline{\mathrm{F}}(1,46)=7.52, \underline{\mathrm{MSE}}=0.06, \underline{\mathrm{p}}<.01$.

Three sets of analysis of variance were conducted to trace to simple effects of cautiousness, speed, and working memory by holding one of the three variables constant. The first set of analysis was a 2 (cautiousness) by 2 (speed) analysis of variance for each working memory recall condition in each serial position. The only significant effects were the cautiousness by speed interactions at serial position 4 in the control condition, $\underline{F}(1,46)=4.31$, $\underline{\mathrm{MSE}}=0.04, \underline{\mathrm{p}}<.05$, and in position 3 in the dual task condition, $\underline{\mathrm{F}}(1,46)=5.76, \underline{\mathrm{MSE}}=0.05, \underline{\mathrm{p}}$ $<.05$. The second set of analysis was a 2 (cautiousness) by 2 (working memory) analysis of variance for each speed condition in each serial position. There only significant effects were the cautiousness by working memory interactions in position 1 of the 3 -syllable condition, $\underline{F}(1,21)$ $=6.49, \underline{\mathrm{MSE}}=0.04, \underline{\mathrm{p}}<.05$, position 3 in the 1 -syllable condition, $\underline{\mathrm{F}}(1,21)=15.11, \underline{\mathrm{MSE}}=$ 
$0.04, \underline{p}<.01$, and position 4 in the 1 -syllable condition, $\underline{\mathrm{F}}(1,21)=15.11, \mathrm{MSE}=0.07, \mathrm{p}<.05$. The third set of analysis was a 2 (speed) by 2 (working memory) analysis of variance for each cautiousness condition in each serial position. The only significant effects were the speed by working memory interactions in serial position 1 in the high cautiousness condition, $\underline{F}(1,22)=$ 9.53, $\mathrm{MSE}=0.04, \mathrm{p}<.01$, position 3 in the high cautiousness condition, $\underline{\mathrm{F}}(1,22)=5.12, \mathrm{MSE}=$ $0.06, \mathrm{p}<.05$, and position 4 in the low cautiousness condition, $\underline{\mathrm{F}}(1,24)=10.12, \mathrm{MSE}=0.06, \mathrm{p}$ $<.01$.

The significant interactions identified in the preceding paragraph were followed up with Fisher LSD tests, which are summarized in Table 7. The effect of cautiousness was significant in the 3-syllable control task in position 1, the 1-syllable control and dual tasks at position 3, the 1syllable control task in position 4 , and the 3 -syllable dual task in position 4 . However, the effect was opposite to expectation for the 1-syllable words in the control task in position 3.

The effect of speed (syllable) was significant in the high cautiousness in control task in position 1 and the low cautiousness control task in position 4. The absence of syllable effect in the dual tasks is consistent with the results obtained by Baddaley et al. (1983), that is, concurrent articulation during encoding eliminates the word-length effect.

The effect of working memory (task) was significant in the low cautiousness 3-syllable condition in position 1 , the low and high cautiousness 1 -syllable conditions in positions 1 and 3 , and the low cautiousness 1-syllable and 3-syllable conditions in position 4 . However, the effect was opposite to expectation for the 1-syllable and 3-syllable words in the low cautiousness condition in position 3 and 4 respectively. 


\section{Effects of Memory Self-Efficacy}

The effects of memory self-efficacy were tested by using analysis of variance, analysis of variance with covariance, and correlational analyses. Analysis of variance was used to compare the recall performance of a subgroup of younger adults who were asked to recall 1-syllable words in the low cautiousness control condition and that of a subgroup of older adults given the same task. Ten younger adults with lower memory self-efficacy scores (mean $=.76, \mathrm{SD}=.09)$ were selected. Ten older adults with relatively high Self Efficacy Level were also selected (mean $=.70$, $\mathrm{SD}=.01)$. The Self Efficacy Level was matched between the two groups, $\underline{\mathrm{F}}(1,18)=0.76, \mathrm{MSE}$ $=0.04, \underline{p}=0.07$. The two groups were found not to differ significantly in recall performance, $\underline{\mathrm{F}}$ $(1,18)=3.21, \underline{\mathrm{MSE}}=2.06, \mathrm{p}=.09$, which indicating that that younger and older adults who are similar in memory self-efficacy are similar in recall performance. This finding implies that memory self-efficacy mediates age differences in free recall. Further analysis showed that the power of the test was $0.30 ; 15$ participants in each age group would be needed to detect the obtained difference. Please also note that the post hoc matching like this one involves regression to the mean even though the matching was done not on the outcome variable but on a variable that was correlated with the outcome variable and even though both variable were measured at the same time.

The effect of memory self-efficacy on memory was also tested by using Self Efficacy Level as a covariate in analyses of the effects of speed, working memory, and cautiousness, and their combined effects. However, the outcome did not support the effects of memory self-efficacy on memory: The effects of age, speed, working memory, cautiousness, and their combined effects on memory were not changed by statistically controlling Self Efficacy Level. These results 
confirmed prediction 6 , that is, the effect of memory self-efficacy was moderate compared with the effects of speed, working memory, and cautiousness. The correlational analysis involving memory self-efficacy is described in the next section.

Table 6.

Mean number of correct responses of the male participants by cautiousness and serial position. Cautiousness Position 1 Position 2 Position 3

Position 4

$\mathrm{n}=14$

Low

2.04

0.86

0.64

2.61

(0.63)

(0.60)

(0.60)

(0.59)

$\mathrm{n}=16$

High

1.66

0.69

1.16

2.03

$(0.54)$

$(0.81)$

$(0.75)$

(0.85)

Note. Standard deviations in parenthesis. 
Table 7

$\underline{\text { Simple effects of cautiousness, speed, and working memory in the female participants }(\mathrm{n}=51)}$

\begin{tabular}{|c|c|c|c|c|c|}
\hline Cautiousness & Speed (Syllable) & Working memory (Task) & Mean 1 & Mean 2 & p \\
\hline \multicolumn{6}{|c|}{ Serial position 1} \\
\hline Low vs High & 1-syllable & Control task & 2.36 & 2.24 & $>.50$ \\
\hline Low vs High & 3-syllable & Control task & 2.24 & 1.26 & $<.01$ \\
\hline Low vs High & 1-syllable & Dual task & 1.72 & 1.32 & $>.10$ \\
\hline Low vs High & 3-syllable & Dual task & 1.68 & 1.80 & $>.60$ \\
\hline Low & 1 vs 3 -syllable & Control task & 2.32 & 2.24 & $>.60$ \\
\hline High & 1 vs 3 -syllable & Control task & 2.24 & 1.28 & $<.05$ \\
\hline Low & 1 vs 3 -syllable & Dual task & 1.68 & 1.64 & $>.05$ \\
\hline High & 1 vs 3 -syllable & Dual task & 1.28 & 1.80 & $>.05$ \\
\hline Low & 1-syllable & Control vs Dual & 2.36 & 1.72 & $<.01$ \\
\hline High & 1-syllable & Control vs Dual & 2.24 & 1.32 & $<.01$ \\
\hline Low & 3-syllable & Control vs Dual & 2.24 & 1.64 & $<.05$ \\
\hline High & 3-syllable & Control vs Dual & 1.28 & 1.80 & $>.20$ \\
\hline \multicolumn{6}{|c|}{ Serial Position 3} \\
\hline Low vs High & a1-syllable & Control task & 0.64 & 1.60 & $<.05$ \\
\hline Low vs High & 3-syllable & Control task & 0.68 & 1.00 & $>.60$ \\
\hline Low vs High & 1-syllable & Dual task & 1.32 & 0.52 & $<.01$ \\
\hline Low vs High & 3-syllable & Dual task & 0.80 & 1.20 & $>.40$ \\
\hline Low & 1 vs 3-syllable & Control task & 0.64 & 0.68 & $>.90$ \\
\hline High & 1 vs 3-syllable & Control task & 1.60 & 1.00 & $>.10$ \\
\hline Low & 1 vs 3-syllable & Dual task & 1.32 & 0.84 & $>.10$ \\
\hline High & 1 vs 3 -syllable & Dual task & 0.52 & 1.20 & $>.10$ \\
\hline
\end{tabular}




\begin{tabular}{|c|c|c|c|c|c|}
\hline Low & ${ }^{\mathrm{a}}$ 1-syllable & Control vs High & 0.64 & 1.36 & $<.05$ \\
\hline High & 1-syllable & Control vs High & 1.60 & 0.52 & $<.01$ \\
\hline Low & 3-syllable & Control vs High & 0.64 & 0.84 & $>.50$ \\
\hline High & 3-syllable & Control vs High & 1.00 & 1.20 & $>.70$ \\
\hline \multicolumn{6}{|c|}{ Serial Position 4} \\
\hline Low vs High & 1-syllable & Control task & 3.36 & 2.32 & $<.01$ \\
\hline Low vs High & 3-syllable & Control task & 2.24 & 2.20 & $>.80$ \\
\hline Low vs High & 1-syllable & Dual task & 2.40 & 2.53 & $>.05$ \\
\hline Low vs High & 3-syllable & Dual task & 3.00 & 1.96 & $<.05$ \\
\hline Low & 1 vs 3 -syllable & Control task & 3.36 & 2.24 & $<.01$ \\
\hline High & 1 vs 3 -syllable & Control task & 2.28 & 2.16 & $>.70$ \\
\hline Low & 1 vs 3 -syllable & Dual task & 2.40 & 3.00 & $>.10$ \\
\hline High & 1 vs 3 -syllable & Dual task & 2.52 & 2.00 & $>.20$ \\
\hline Low & 1-syllable & Control vs High & 3.36 & 2.44 & $<.10$ \\
\hline High & 1-syllable & Control vs High & 2.32 & 2.53 & $>.50$ \\
\hline Low & a3-syllable & Control vs High & 2.24 & 2.50 & $<.05$ \\
\hline High & 3-syllable & Control vs High & 2.20 & 1.96 & $>.60$ \\
\hline
\end{tabular}




\section{Individual-Differences Data}

The central concern from the individual-differences perspective is the role of processing resources (working memory and speed of processing) and memory self-efficacy in age differences in free-recall performance. Hierarchical regression analyses were conducted to see whether processing resources and memory self-efficacy played a meaningful role in the age differences in recall, and also to compare the present data with other related studies (e.g., Bryan \& Luszcz, 1996; Park et al., 1996). The analyses were conducted only on the data from the younger adults in the low cautiousness 1-syllable control group and the older adults in the low cautiousness 1-syllable control group. Older adults' recall performance was measured by the number of words recalled on list B in the second list, because both groups had the same stimuli and were in the same list.

Table 8 presents the means and standard deviations for the test of Self Efficacy Level, Self Efficacy Strength Level, Forward Digit Span, Backward Digit Span, Computation-span, Finding A's, and Digit Symbol Substitution test in all groups. The split-half reliability of the Finding A's test corrected with the Spearman-Brown formula was 0.92 for all participants. As can be seen in the table, the four young groups outperformed the old on processing speed, working memory, and memory self-efficacy level measures, but did not differ from each other. Age difference was not significant for SESL, which is consistent with Berry et al. (1989) (prediction 9). 
Table 8

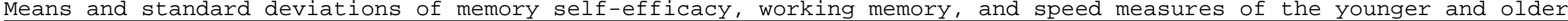
adults $(\mathrm{n}=120)$

\begin{tabular}{|c|c|c|c|c|c|c|c|c|c|c|c|c|}
\hline \multirow[b]{4}{*}{ Variable } & \multicolumn{8}{|c|}{ Young } & \multicolumn{4}{|c|}{ Old } \\
\hline & \multicolumn{4}{|c|}{ Low Cautiousness } & \multicolumn{4}{|c|}{ High Cautiousnes } & \multicolumn{4}{|c|}{ Low Cautiousness } \\
\hline & \multicolumn{2}{|c|}{1 -syllable } & \multicolumn{2}{|c|}{ 3-syllable } & \multicolumn{2}{|c|}{1 -syllable } & \multicolumn{2}{|c|}{ 3-syllable } & \multicolumn{2}{|c|}{1 -syllable } & \multicolumn{2}{|c|}{ 3-syllable } \\
\hline & M & SD & M & $\mathrm{SD}$ & M & $\mathrm{SD}$ & M & $\mathrm{SD}$ & $\mathrm{M}$ & $\mathrm{SD}$ & M & $\mathrm{SD}$ \\
\hline \multicolumn{13}{|c|}{ Self-Efficacy } \\
\hline SESL & 0.73 & 0.12 & 0.70 & 0.15 & 0.73 & 0.13 & 0.71 & 0.12 & 0.70 & 0.17 & 0.70 & 0.09 \\
\hline SEL & 0.83 & 0.11 & 0.85 & 0.10 & 0.87 & 0.11 & 0.82 & 0.12 & 0.64 & 0.08 & 0.66 & 0.26 \\
\hline \multicolumn{13}{|c|}{ Working Memory } \\
\hline BD-Span & 7.60 & 1.88 & 7.45 & 1.82 & 7.80 & 1.77 & 7.70 & 2.08 & 5.45 & 1.32 & 5.75 & 1.25 \\
\hline FD-Span & 9.00 & 1.84 & 8.30 & 1.89 & 8.70 & 2.08 & 10.25 & 1.48 & 7.80 & 1.01 & 6.90 & 0.97 \\
\hline \multicolumn{13}{|l|}{ Speed } \\
\hline Finding $\mathrm{A}$ & 67.05 & 17.83 & 65.25 & 20.79 & 71.50 & 20.80 & 64.75 & 19.42 & 44.15 & 11.41 & 44.75 & 16.74 \\
\hline DSST & 73.50 & 13.35 & 75.40 & 11.17 & 78.85 & 9.11 & 70.85 & 13.81 & 46.65 & 11.17 & 44.75 & 16.74 \\
\hline
\end{tabular}

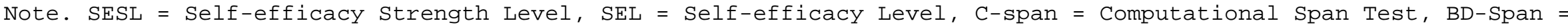

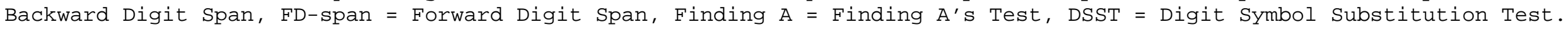


Table 9

Pearson correlation coefficients among measures of memory self-efficacy, working memory, speed, sex, syllable, cautiousness, and recall performance of all participants in the control condition (n = 120)

\begin{tabular}{|c|c|c|c|c|c|c|c|c|c|c|c|}
\hline Variable & SESL & SEL & C-span & BD-span & FD-span & Finding $\mathrm{A}$ & DSST & Sex & Syllable & Cautiousness & Recall \\
\hline SEL & $0.25 * \star$ & & & & & & & & & & \\
\hline C-span & -0.11 & $0.26 * \star$ & & & & & & & & & \\
\hline BD-span & 0.07 & $0.31 * \star$ & 0.07 & $0.51 * \star$ & & & & & & & \\
\hline Finding $\mathrm{A}$ & -0.11 & $0.19 *$ & $0.36 * *$ & $0.47 * \star$ & $0.28 * \star$ & & & & & & \\
\hline DSST & 0.06 & $0.33 * \star$ & $0.42 * \star$ & $0.53 * \star$ & $0.32 * \star$ & $0.69 * \star$ & & & & & \\
\hline Sex & $0.21 *$ & 0.09 & -0.04 & 0.13 & 0.17 & $-0.19 *$ & -0.09 & & & & \\
\hline Syllable & -0.07 & 0.01 & -0.13 & 0.02 & 0.00 & -0.02 & -0.06 & 0.06 & & & \\
\hline Cautiousness & 0.03 & $0.28 * \star$ & 0.17 & $0.31 * \star$ & $0.37 * \star$ & $0.27 * \star$ & $0.37 * \star$ & 0.04 & 0.00 & & \\
\hline Recall & 0.05 & 0.15 & $0.41 * \star$ & $0.44 * \star$ & $0.44 * \star$ & $0.55 * \star$ & $0.60 * \star$ & -0.02 & $-0.32 \star \star$ & -0.11 & \\
\hline Age & -0.07 & $-0.56 \star \star$ & $-0.34 \star \star$ & $-0.52 \star \star$ & $-0.42 \star \star$ & $-0.47 \star \star$ & $-0.73 \star \star$ & 0.00 & 0.00 & $-0.50 \star \star$ & $-0.40 * \star$ \\
\hline
\end{tabular}

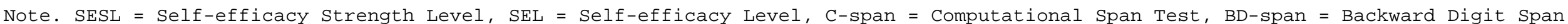

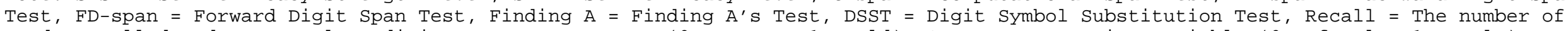

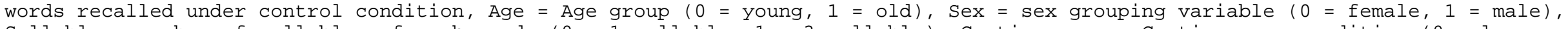

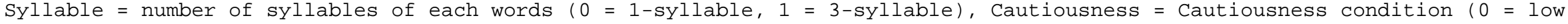
cautiousness, 1 = high cautiousness).

$\star \mathrm{p}<.05$

$\star \star p<.01$ 
Table 9 shows the correlations among the variables. Recall performance was positively correlated with the processing speed and working memory measures, and negatively correlated with age (prediction 7 and 8). Recall was not correlated with either Memory Self Efficacy Level or Memory Self Efficacy Strength Level, which contradicted with prediction 10. Participants in the high cautiousness conditions tended to have higher scores on the processing speed, working memory, and memory self-efficacy. Male participants tended to be higher than females in memory self-efficacy, but females had higher processing speed score than males.

$\underline{\text { Hierarchical regression analyses. Hierarchical regression analyses were conducted to test }}$ the mediating effects of memory self-efficacy, processing speed, and working memory on age-related differences in free recall performance. Table 10 presents the hierarchical regression equations. Age was entered last in all of the equations except Equation 1, in which it was the only predicator. Equation 1 shows that age accounted for $27 \%$ of variance in recall. Equations 2 through 8 were used to test the mediating effect role of each variable on age differences in recall. Self Efficacy Strength Level did not produce significant effects on age difference in recall (Equation 2) (prediction 11). Therefore, Memory Self Efficacy Level and Memory Self Efficacy Strength Level were omitted from the subsequent equations. Self Efficacy Level, processing speed, and working memory accounted for significantly amounts of variance in recall (Equations 3 through 8).

Pairs of conceptual similar predictions were entered before age in Equation 9 through 16. Equations 9 and 10 assessed the relative importance of the two speed measures compared to age. Both accounted for significant variance and accounted for the effect of age (prediction 11). Whichever speed measure was entered first accounted for much more variance than the one 
entered second.

Equations 11 through 16 assessed the relative importance of pairs of working memory variables compared to age. The pattern of results indicated that Backward Digit Span and Computation-span was a more powerful predictor than Forward Digit span and together accounted for the effects of age (Equation 15 and 16). Therefore, Forward Digit span was omitted from the subsequent equations. These results are consistent with previous findings regarding the validity of these tests as the measures of working memory.

Pairs of conceptually different predicators were entered before age in the rest of the equations. Equation 17 through 20, with self-efficacy and speed, and Equations 21 through 24, with self-efficacy and working memory, show that self-efficacy did not account for effects of speed and working memory but was accounted for by speed and working memory (predication 12).

Equations 25 through 32 assessed the relative importance of processing speed and working memory and age in recall. Forward Digit Span was excluded from the tests, because equation 12 and 14 have shown that more age-related variable in free recall was accounted for by the Backward Digit Span. Age had no effect in any of these equations and with one exception, speed and working memory had independent effects (predication 13). The exception was that entering the Digit Symbol Substitution measured of speed first eliminated the effect of working memory measured by the Backward Digit Span. 
Table 10

Hierarchical multiple regression analyses predicating the number of words recalled from age, SEL, SESL, FD-span, BD-span, C-span, Finding A, and DSST $(\mathrm{n}=40)$

\begin{tabular}{|c|c|c|c|c|}
\hline Equation & Variable & $\underline{\mathrm{R}^{2}}$ & $\underline{\mathrm{R}^{2}}$ change & F change \\
\hline 1 & Age & 0.27 & 0.27 & $14.25^{* * *}$ \\
\hline \multirow[t]{2}{*}{2} & SESL & 0.04 & 0.04 & 1.79 \\
\hline & Age & 0.27 & 0.23 & $11.66 * *$ \\
\hline \multirow[t]{2}{*}{3} & SEL & 0.14 & 0.14 & $6.14 *$ \\
\hline & Age & 0.27 & 0.13 & $6.81 *$ \\
\hline \multirow[t]{2}{*}{4} & Finding A & 0.31 & 0.31 & $17.59 * * *$ \\
\hline & Age & 0.36 & 0.05 & 2.18 \\
\hline \multirow[t]{2}{*}{5} & DSST & 0.35 & 0.35 & $20.45^{* * *}$ \\
\hline & Age & 0.36 & 0.01 & 0.74 \\
\hline \multirow[t]{2}{*}{6} & FD-span & 0.16 & 0.16 & 7.91 *** \\
\hline & Age & 0.32 & 0.16 & $8.68 * *$ \\
\hline \multirow[t]{2}{*}{7} & BD-span & 0.21 & 0.21 & $10.36^{* * * *}$ \\
\hline & Age & 0.29 & 0.08 & $4.28 *$ \\
\hline \multirow[t]{2}{*}{8} & C-span & 0.23 & 0.23 & $11.67 * * *$ \\
\hline & Age & 0.34 & 0.11 & $8.42 * *$ \\
\hline \multirow[t]{3}{*}{9} & Finding A & 0.31 & 0.31 & $17.59 * * *$ \\
\hline & DSST & 0.39 & 0.08 & $4.63^{*}$ \\
\hline & Age & 0.40 & 0.01 & 0.02 \\
\hline \multirow[t]{3}{*}{10} & DSST & 0.35 & 0.35 & $20.45^{* * *}$ \\
\hline & Finding A & 0.46 & 0.11 & $4.17^{*}$ \\
\hline & Age & 0.47 & 0.01 & 0.03 \\
\hline \multirow[t]{3}{*}{11} & FD-span & 0.16 & 0.16 & 7.91 *** \\
\hline & BD-span & 0.25 & 0.09 & $4.50^{*}$ \\
\hline & Age & 0.33 & 0.08 & $4.10 *$ \\
\hline \multirow[t]{3}{*}{12} & BD-span & 0.21 & 0.21 & $10.36^{* * *}$ \\
\hline & FD-span & 0.26 & 0.05 & 1.95 \\
\hline & Age & 0.33 & 0.07 & $4.10 *$ \\
\hline \multirow[t]{3}{*}{13} & FD-span & 0.16 & 0.16 & $7.91 * * *$ \\
\hline & C-span & 0.24 & 0.08 & $9.77 *$ \\
\hline & Age & 0.32 & 0.08 & $5.21 *$ \\
\hline \multirow[t]{2}{*}{14} & C-span & 0.23 & 0.23 & $11.67 * * *$ \\
\hline & FD-span & 0.29 & 0.06 & 3.19 \\
\hline
\end{tabular}




\begin{tabular}{|c|c|c|c|c|}
\hline & Age & 0.37 & 0.08 & $4.71^{*}$ \\
\hline \multirow[t]{3}{*}{15} & BD-span & 0.21 & 0.21 & $10.36 * * *$ \\
\hline & C-span & 0.34 & 0.13 & $7.29 * *$ \\
\hline & Age & 0.37 & 0.03 & 2.09 \\
\hline \multirow[t]{3}{*}{16} & C-span & 0.23 & 0.23 & $11.67 * * *$ \\
\hline & BD-span & 0.33 & 0.10 & $5.74 *$ \\
\hline & Age & 0.37 & 0.04 & 2.07 \\
\hline \multirow[t]{3}{*}{17} & SEL & 0.14 & 0.14 & $6.14 *$ \\
\hline & Finding A & 0.31 & 0.17 & $16.23 * * *$ \\
\hline & Age & 0.38 & 0.07 & $4.15^{*}$ \\
\hline \multirow[t]{3}{*}{17} & Finding A & 0.31 & 0.31 & $17.59 * * *$ \\
\hline & SEL & 0.32 & 0.01 & 1.21 \\
\hline & Age & 0.37 & 0.05 & 2.45 \\
\hline \multirow[t]{3}{*}{18} & SEL & 0.14 & 0.14 & $6.14 *$ \\
\hline & DSST & 0.40 & 0.26 & $16.12 * * *$ \\
\hline & Age & 0.43 & 0.03 & 1.92 \\
\hline \multirow[t]{3}{*}{20} & DSST & 0.35 & 0.35 & $20.45^{* * *}$ \\
\hline & SEL & 0.36 & 0.01 & 0.01 \\
\hline & Age & 0.37 & 0.01 & 0.87 \\
\hline \multirow[t]{3}{*}{21} & SEL & 0.14 & 0.14 & $6.14 *$ \\
\hline & BD-span & 0.21 & 0.07 & $5.67 *$ \\
\hline & Age & 0.42 & 0.21 & $0.21^{* * * *}$ \\
\hline \multirow[t]{3}{*}{22} & BD-span & 0.21 & 0.21 & $10.36 * * *$ \\
\hline & SEL & 0.22 & 0.01 & 1.01 \\
\hline & Age & 0.42 & 0.20 & $19.20 * * *$ \\
\hline \multirow[t]{3}{*}{23} & SEL & 0.14 & 0.14 & $6.14^{*}$ \\
\hline & C-span & 0.32 & 0.18 & $19.18 * * *$ \\
\hline & Age & 0.42 & 0.10 & $8.23 * *$ \\
\hline \multirow[t]{3}{*}{24} & C-span & 0.23 & 0.23 & $11.67 * * *$ \\
\hline & SEL & 0.28 & 0.05 & 2.49 \\
\hline & Age & 0.35 & 0.07 & $4.10 *$ \\
\hline \multirow[t]{3}{*}{25} & Finding A & 0.31 & 0.31 & $17.59 * * *$ \\
\hline & BD-span & 0.40 & 0.09 & $5.56^{*}$ \\
\hline & Age & 0.41 & 0.01 & 0.52 \\
\hline \multirow[t]{3}{*}{26} & BD-span & 0.21 & 0.21 & $10.36 * * *$ \\
\hline & Finding A & 0.40 & 0.19 & $11.29 * * *$ \\
\hline & Age & 0.41 & 0.01 & 0.23 \\
\hline \multirow[t]{2}{*}{27} & Finding A & 0.31 & 0.31 & $17.59 * * *$ \\
\hline & C-span & 0.41 & 0.10 & $6.18^{*}$ \\
\hline
\end{tabular}




$\begin{array}{clccc} & \text { Age } & 0.43 & 0.02 & 1.02 \\ 28 & & & 0.23 & 11.67^{* * * *} \\ & \text { C-span } & 0.23 & 0.17 & 11.22^{* * *} \\ & \text { Finding A } & 0.40 & 0.02 & 1.20 \\ \text { Age } & 0.42 & & 20.45^{* * *} \\ & & & 0.35 & 2.29 \\ & \text { DSST } & 0.35 & 0.04 & 0.23 \\ & \text { BD-span } & 0.39 & 0.01 & 10.36^{* * *} \\ & \text { Age } & 0.40 & & 10.73^{* * *} \\ & & & 0.21 & 0.23 \\ & \text { BD-span } & 0.21 & 0.18 & 20.45^{* * *} \\ & \text { DSST } & 0.39 & 0.01 & 4.14^{*} \\ & \text { Age } & 0.40 & 0.35 & 0.45 \\ & \text { DSST } & & 0.07 & 11.67^{* * *} \\ & \text { C-span } & 0.35 & 0.01 & 11.29^{* * *} \\ & \text { Age } & 0.42 & & 1.20\end{array}$

Note: Age $=$ age group $(0=$ young, $1=$ old $)$, Sex $=$ sex grouping variable $(0=$ female, $1=$ male $)$, syllable $=$ number of syllables in the words $(0=1$-syllable, $1=3$-syllable $)$, Cautiousness $=$ cautiousness condition $(0=$ low cautiousness, 1 $=$ high cautiousness), SESL = Self-Efficacy Strength Level, SEL = Self-Efficacy Level, C-span = Computation-span Test, BD-span = Backward Digit Span Test, FD-span = Forward Digit Span Test, Finding A = Finding A's Test, DSST $=$ Digit Symbol Substitution Test, Recall $=$ number of words recalled under control condition .

$$
\begin{aligned}
* \mathrm{p} & <.05 \\
* * \mathrm{p} & <.01 \\
* * * \mathrm{p} & <.001
\end{aligned}
$$




\section{Discussion}

The main findings from this study are as follows. First, processing speed was important in explaining age differences in free recall. The experimental data indicated that in younger adults, reduced processing speed produced a level of recall performance similar to that of the old (predication 3). Reduced processing speed also enlarged the age differences in recall in that the older adults recalled significantly fewer 3-syllable words than 1-syllable words (predication 2). The findings from the experimental manipulation were supported by correlational data in which speed accounted for a large amount of variance in age-related memory performance, which suggested that speed is a mediator for aging memory (predication 11). Second, working memory was another important construct for aging memory. Artificially reducing working memory capacity by a dual task manipulation in the younger adults produced the same level of free recall performance as in the old (predication 4). Correlational data suggested that working memory, along with speed, can explain age-related variance in free recall (predication 13). Third, cautiousness cannot be ignored in age memory. The experimental manipulation of cautiousness in the younger adults generated much reduced memory performance (predication 5). Fourth, memory self-efficacy had some effects on aging memory, but its effects were rather moderate (predication 6 and 12). Finally, the effects of speed, working memory, and cautiousness were additive in that no interactions of these three variables were found in the younger adults (predication 1).

The present findings are consistent with the work of Bryan and Luszcz (1996), Park et al. (1996) and Salthouse $(1980,1993 b, 1994,1996)$ in that speed was the fundamental component of age-related variations in memory. The experimental data are consistent with Salthouse (1980), in 
which the younger adults recalled significantly fewer 3-syllable words than 1-syllable words. Furthermore, the serial position functions in the younger adults recalled 1-syllable and 3-syllable words were the same. The correlational data indicated that age-related variance in free recall performance was mediated by processing speed, as measured by perceptual speed. A number of studies have found the same result across different cognitive tasks, including reasoning and integration (Salthouse, 1993b), paired-associates and free-recall measures of memory (Huang, 1996, Linderberger et al., 1993; Salthouse, 1993b), fluency and knowledge (Linderberger et al., 1993), and decision accuracy and decision time (Salthouse, 1994). Many studies interested in speed effects are not included working memory. The present study included both speed and working memory measures. The results show that the role of speed is indeed important, but it operates in part through working memory. That is, the age-related variance works entirely through speed but that speed and working memory jointly contribute to memory function. This result is consistent with the model purposed by Park et al. (1996) and with the suggestions from Mayr and Kliegl (1993), Kliegl et al. (1994), and Nettelbeck and Rabbitt (1992) which indicated that additional factors, such as working memory, predicated memory performance.

The present study provides some support for processing resource views of aging memory. Craik and Byrd (1982) have hypothesized that older adults are limited in self-initiated processing abilities and that this accounts for age differences in memory. Limitations in self-initiated processing would occur if there were limitations in processing resources. Salthouse (1991b) suggested that both speed and working memory could be indexes of general processing resources. The data from present study support this processing resources view in that experimental manipulation of speed and working memory has produced significant effects on 
recall performance and regression analyses indicated that speed and working memory measures accounted for age-related variance in recall. These results are consistent with the predication made by the processing resources view. As Park et al. (1996) pointed out that speed is a more fundamental mechanism or resource and that it is speed that mediates age-related variance in working memory, which in turn predicts memory performance. Park et al.'s (1996) hypothesis was supported in this study which speed reduced the effects of working memory more substantially than working memory did for speed in predicting age differences in memory. It is likely that slower speed reduce the efficiency of working memory and such decline in efficiency may impair more effortful type of memory, such as free recall, but not in the other memory tasks which require low resources demand, such as implicit memory. Future studies are needed to examine the mechanisms in those types of memory. For example, there is little age-related variance on implicit memory tasks (Park \& Shaw, 1992), so it would likely be only variance that is not common with age that would predict memory, but not speed, not working memory.

One might also fruitfully consider an alternative relation between speed and working memory. That is, the slower speed in older adults might be a consequence of reduced working memory capacity. Multiple syllable words do reduce the processing speed, but they also reduce the capacity of working memory (Baddeley, 1986). Furthermore, the concurrent digit recall during learning does not simply reduce working memory capacity per se, but, in dividing attention and blocking off part of articulation, it presumably slows the processing of information. Word-length effect causes reduced working memory capacity and concurrent digit recall causes slowing, which causes poorer memory performance. Therefore, one speculation from these results is that an age-related speed reduction is the consequence of an age related working 
memory reduction rather than the direct cause of the memory deficit. If speed is not the unique and causal factor for memory performance, then (for example) increasing study time might often fail to compensate for age differences in memory performance (Craik \& Rabinowitz, 1985; Rabinowitz, 1989).

This study demonstrated that aging memory is the product of multiple factors and including only speed and working memory as processing resources in explaining aging memory may not be sufficient. The experimental data from cautiousness manipulation show that the effects of cautiousness cannot be neglected. It is clear that age differences in cognitive performance represent not only a decline in the ability being tested, but also the cautiousness level of older adults (Schaie \& Willis, 1991). The declined recall performance in high cautiousness condition demonstrated the effects of cautiousness, but the still remained age differences in recall may be the reflection of actual decline in ability. Future research is needed to further identify the effects of cautiousness on age differences in memory by using more refined methods, such as Signal Detection Theory. It may be also fruitful to measure cautiousness psychometrically and examine its mediation role along with speed and working memory by using correlational techniques, such as hierarchical regression and structural equation modeling. The merit of this is providing convergent evidence to the causes of age differences in memory performance.

This study examined the role of memory self-efficacy and generated some interesting results. Memory self-efficacy plays an important role in mediating age differences in memory, but its role is less central than speed and working memory. The similar level of recall performance of 10 younger adults with low memory self-efficacy scores and 10 older adults suggested that 
memory self-efficacy might be critical for memory. However, the younger adults recalled more words than the older adults did. Further analyses revealed that such comparison has a lower power $($ power $=0.30)$; adding only 5 participants in each group could obtain a significant difference on recall between these two groups with equivalent Memory Self Efficacy Level. Furthermore, using Memory Self Efficacy Level as a covariable in the analyses of speed, working memory, and cautiousness and their combined effects produced nonsignificant effects. Regression analyses revealed that when speed and working memory were controlled, Self Efficacy Level no longer accounted for significant amount of variance in recall (see Reese, in press, for a detailed discussion on null hypothesis testing). These results suggested that memory self-efficacy has a much less central role in explaining age differences in free recall performance. It is not clear whether memory self-efficacy would have better predictive validity in other types of memory tasks, such as prospective memory and everyday memory. Future research on the effects of memory self-efficacy on prospective and everyday memory will be rewarding in that mechanisms underlying prospective and everyday functions appear to be different from those associated with other measures of explicit memory tested in the laboratory settings (Einstein \& McDaniel, 1990).

The absence of age differences in Self Efficacy Strength Level is consistent with Berry et al. (1989). This result has been considered as an indication that older adults tend to have same level of confidence ratings as the young. Given the fact that older adults have lower SEL than younger adults, it is very likely that older adults may have felt the need to be more confidant when giving yes responses. This result is consistent with age-related studies of response bias and omission error, in that younger adults often adopt relatively stricter decision criteria than the 
young (Botwinick, 1984; Danziger, 1980). As Berry et al. (1989) pointed out that higher Self Efficacy Level reflects a person's view of his/her skill level and Self Efficacy Strength Level represents a person's confidence level. This result once again confirmed that older adults have a higher level of cautiousness than the young and this phenomenon may be more significant when high cognitive demands are needed, which is the case in free recall.

The present study also demonstrates the usefulness of the simulation strategy (Baltes, et al. 1988; Salthouse, 1991). Direct manipulation of age-related variables can provide insights into the meaning of age differences and enhance theory-oriented research (Baltes \& Goulet, 1971, p. 164). However, aging effects reflect multiple causes; therefore, any attempt to simulate an aging effect by manipulating one or a few variables is troublesome. In this study, three variables were included and the results were more convincing. Furthermore, this kind of manipulation permits one to investigating any interactions among multiple variables, which any moderate effects can be identified and more detailed information can be obtained. Another merit of simulation strategy is its power to test theory. Every simulation manipulation has to be based existing theory. The results from simulation studies can test the validity of the theory and provide replication of existing data. As in this study, the word-length effect and the dual task effect on the word-length effect were replicated. In addition, a failure of the simulation research could generate more questions on theory construction. Of course, one may criticize the external validity of simulation (Baltes, et al. 1988; Hultsch \& Hickey, 1978), that is, whether the treatments represent the intended underlying processes--the issue of construct validity (Cook \& Campell, 1979). There is no easy solution to this problem, because it applies to any type of experimentation (Baltes, et al., 1988). 
The present study illustrates the value of a combined experimental and individualdifferences approach. Park et al. (1996) noted that the individual-differences technique is a valuable way to explore aging effects and adjudicate alternative theories. They also noted, however, that the technique might work best in combination with an experimental approach, using a "hybrid methodology" in that the individual differences approach does have limitations, such as subjective selection of models and measurement. It is demonstrated in this study that using Backward Digit Span as a working memory measure has less predicative validity than Computation-span. Research based on Backward Digit Span or Backward Word span normally produce much weaker prediction and less likely support the role of working memory in aging memory (e.g., Bryan \& Luszcz, 1996). This kind of bias can lead to much serious problems in theory construction and provide wrong direction of future research. A combined experimental and individual-differences approach can reduce such risks by simultaneously test hypotheses. The present study illustrates the utility of such an approach, and further work using this approach will elucidate further subtle characteristics of age-related changes in memory and cognition.

In summary, the present study confirms and extends recent descriptions of age-related changes in free recall (Bryan \& Luszcz, 1996; Park et al., 1996). It also brings the literature on the social aspects of aging and cognitive aging together. That literature is not simple, however and further work remains to be done on articulating some of the specifics of the characteristics of the relation between processing resources and variables in the social domain of aging, such as cautiousness and memory self-efficacy. 


\section{References}

Alpaugh, P. K., \& Birren, J. E. (1977). Variables affecting creative contributions across the adult life span. Human Development, 20, 240-248.

Anders, T. R., \& Fozard, J. L. (1973). Effects of age upon retrieval from primary and secondary memory. Developmental Psychology, 9, 411-415.

Anders, T. R., Fozard, J. L., \& Lillyquist, T. D. (1972). Effects of age upon retrieval from shortterm memory. Developmental Psychology, 6, 214-217.

Bäckman. L. (1986). Adult age differences in cross-modal recoding and mental tempo, and older adults' utilization of compensatory task conditions. Experimental Aging Research, 12, 135-140.

Baddeley, A. (1986). Working memory. New York: Oxford University Press.

Baddeley, A., Lewis, V., Eldridge, M., \& Thomson, N. (1984). Attention and retrieval from long-term memory. Journal of Experimental Psychology: General, 13, 518-540.

Baltes, P. B., \& Goulet, L. R. (1971). Exploration of developmental variables by manipulation and simulation of age differences in behavior. Human Development, 14, 149-170.

Baltes, P. B., Reese, H. W., \& Nesselroade, J. R. (1988). Life-span developmental psychology: Introduction to research methods. Hillsdale, NJ: Erlbaum.

Bandura, A. (1977). Self-efficacy: Toward a unifying theory of behavioral change. Psychological Review, 84, 191-215.

Bandura, A. (1986). Social foundations of thought and action: A social cognitive theory. Englewood Cliffs, NJ: Prentice-Hall.

Banks, W. P. (1970). Signal detection theory and human memory. Psychological Bulletin 74, 
81-99.

Bashore, T. R., Osman, A., \& Heffley, E. F. (1989). Mental slowing in elderly persons: A cognitive psychophysiological analysis. Psychology and Aging, 4, 235-244.

Berry, J. M., \& West, R. L. (1993). Cognitive self-efficacy in relation to personal mastery and goal setting across the life span. International Journal of Behavioral Development, 16, 351-379.

Berry, J. M., West, R. L., \& Dennehey, D. M. (1989). Reliability and validity of the memory self-efficacy questionnaire. Developmental Psychology, 25, 701-713.

Birkhill, W. R., \& Schaie, K. W. (1975). The effect of differential reinforcement of cautiousness in the intellectual performance of the elderly. Journal of Gerontology, 30, 578-583.

Birren, J. E. (1964). The psychology of aging. Englewood Cliffs, NJ: Prentice-Hall.

Birren, J. E. (1965). Age changes in speed of behavior: Its central nature and physiological correlates. In A. T. Welford \& J. E. Birren (Eds.), Behavior, aging and nervous system (pp. 191-216). Springfield, IL: Charles C Thomas.

Birren, J. E., Riegal, K. F., \& Morrison, D. F. (1962). Age differences in response speed as a function of controlled variations of stimulus conditions: Evidence of a general speed factor. Gerontologia, 6, 1-18.

Birren, J. E., \& Shaie, K W. (Eds.). (1995). Handbook of the Psychology of aging (4th ed.). New York: Academic Press.

Botwinick, J. (1966). Cautiousness in advanced age. Journal of Gerontology, 21, 347-353.

Botwinick, J. (1978). Aging and behavior. New York: Springer.

Botwinick, J., Brinley, J. F., \& Robbin, J. S. (1958). The interaction effects of perceptual 
difficulty and stimulus exposure time on age differences in speed accuracy of response. Gerontologia, 2, 1-10.

Brinley, J. F. (1965). Cognitive sets, speed and accuracy of performance in the elderly. In A. T. Welford \& J. E. Birren (Eds.), Behavior, aging and the nervous system (pp. 114-149). Springfield, IL: Charles C Thomas.

Bromley, D. B. (1963). Age differences in conceptual abilities. In R. H. Williams, C. Tibbitts, \& W. Donahue (Eds.), Processes of aging (Vol. 2, pp. 96-113). New York: Atherton.

Bromley, D. B. (1967). Age and sex differences in the serial production of creative conceptual response. Journal of Gerontology, 22, 32-42.

Bruce, P. R., Coyne, A. C., \& Botwinick, J. (1982). Adult age differences in metamemory. Journal of Gerontology, 37, 354-357.

Bryan, J., \& Luszcz, M. A. (1996). Speed of information processing as a mediator between age and free-recall performance. Psychology and Aging, 11, 3-9.

Byrne, B. M. (1994). Structural equation modeling with EQS and EQS/Windows: Basic concepts, applications, and programming. Thousand Oaks, CA: SAGE.

Cavanaugh, J. C., \& Poon, L. W. (1989). Metamemorial predicators of memory performance in young and older adults. Psychology and Aging, 4, 365-368.

Cerella, J., Poon, L. W., \& Williams, D. M. (1980). Aging and complexity hypothesis. In L. W. Poon (Ed.), Aging in the 1980s: Psychological issues (pp. 332-340). Washington, DC: American Psychological Association.

Cerella, J. (1985). Information processing rates in the elderly. Psychological Bulletin, 98, 67-83. Cerella, J. (1990). Aging and information-processing rate. In J. E. Birren \& K. W. Shaie (Eds.), 
Handbook of the psychology of aging (3rd ed., pp. 102-121).New York: Academic Press.

Cerella, J., Poon, L. W., \& Williams, D. M. (1980). Aging and complexity hypothesis. In L. W. Poon (Ed.), Aging in the 1980s: Psychological issues (pp. 332-340). Washington, DC:American Psychological Association.

Charness, N. (1985). Aging and problem-solving performance. In N. Charness (Ed.), $\underline{\text { Aging and }}$ human performance (pp. 225-259). Chichester: Wiley.

Charness, N. (1987). Component processes in bridge bidding and novel problem-solving tasks. Canadian Journal Psychology, 41, 223-243.

Cohen, G. (1979). Language comprehension in old age. Cognitive Psychology, 11, 412-429.

Craik, F. 1. M. (1969). Applications of signal detection theory to studies of aging. Interdisciplinary Topics of Gerontology, 4, 147-157.

Craik, F. I. M. (1977). Age differences in human memory. In J. E. Birren \& K. W. Schaie (Eds.), Handbook of the psychology of aging (pp. 384-420). New York: Van Nostrand Reinhold.

Craik, F. I. M. (1983). On the transfer of information from temporary to permanent memory. Philosophical Transactions of the Royal Society, London, B302, 341-359.

Craik, F. I. M. (1986). A functional account of age differences in memory. In F. Klix \& H. Hagendof (Eds.), Human memory and cognitive capabilities (pp. 409-422). Amsterdam: North-Holland.

Craik, F. 1. M., \& Byrd, M. (1982). Aging and cognitive deficits: The role of attentional resources. In F. 1. M. Cralk \& S. Trehub (Eds.), Aging and cognitive processes (pp. 191211). New York: Plenum.

Craik, F. 1. M., \& Rabinowitz, J. C. (1985). The effects of presentation rate and encoding task 
on age-related memory deficits. Journal of Gerontology, 40, 309-315.

Crossman, E. R. F. W., \& Szafran, J. (1956). Changes with age in the speed of informationintake and discrimination. Experientia Supplementum IV. Symposium on Experimental Gerontology (pp. 128-135). Basel: Birkhauser.

Dixon, R. A. (1989). Questionnaire research on metamemory and aging: Issues of structure and function. In L. Poon, D. Rubin, \& B. Wilson (Eds.), Everyday cognition in adulthood and late life. (pp. 78-93) Cambridge, MA: Cambridge University Press.

Dixon, R. A., \& Hultsch, D. F. (1983a). Structure and development of metamemory in adulthood. Journal of Gerontology, 38, 689-694.

Dixon, R. A., \& Hultsch, D. F. (1983b). Metamemory and memory for text relationships in adulthood. Journal of Gerontology, 38, 689-694.

Erber, J. T., Herman, T. G., \& Botwinick, J. (1980). Age differences in memory as a function of depth of processing. Experimental Aging Research, 6, 341-348.

Eriksen, C. W., \& Hamlin, R. M., \& Daye, C. (1973). Aging adults and rate of memory scan. Bulletin of the Psychonomic Society, 1, 259-260.

Fisher, R. A. (1935). The design of experiments. Edinburgh: Oliver \& Boyd.

Fisk, J. E., \& Warr, P. (1996). Age and working memory: The role of perceptual speed, the central executive, and the phonological loop. Psychology and Aging, 11, 316-323.

Foo, P. W. (1989). Adult age differences in working memory. Psychology and Aging, 4, 269275.

Ford, J. M., Roth, W. T., Mohs, R. C., \& Hopkins, B. S. (1979). Event-related potentials recorded from young and old adults during a memory retrieval task. 
Electroencephalography and Clinical Neurophysiology, 47, 450-459.

Fozard, J. L., \& Thomas, J. C. (1975). Psychology of aging: Basic findings and some psychiatric applications. In J. G. Howells (Ed.), Modern perspectives in the psychiatry of old age (pp. 107-169). New York: Brunner/Masel.

Frieske, D. A., \& Park, D. C. (1993). Effect of organization and working memory on age differences in memory for scene information. Experimental Aging Research, 19, 321332.

Gergen, K. J., \& Back, K. W. (1966). Communication in the interview and the disengaged respondent. Public Opinion Quarterly, 30, 385-398.

Gordon, S. K., \& Clark, W. C. (1974a). Adult age differences in word and nonsense syllable recognition memory and response criterion. Journal of Gerontology, 29, 659-665.

Gordon, S. K., \& Clark, W. C. (1974b). Application of signal detection theory to prose recall and recognition in elderly and young adults. Journal of Gerontology, 29, 64-72.

Gregory, R. L. (1957). Increase in "neurological noise" as a factor in aging. Proceedings of the $4^{\text {th }}$ Congress of the International Association of Gerontology (pp. 314-324). Merano, Italy.

Guttentag, R. E. (1988). Processing retional and item-specific informaion: Effects of aging and division of attention. Canadian Journal of Psychology, 42, 414-423.

Harkins, S. W., Chapman, C. R., \& Eisdorfer, C. (1979). Memory loss and response bias in senescence. Journal of Gerontology, 34, 66-72.

Hasher, L., \& Zacks, R. T. (1988). Working memory, comprehension and aging: A review and a new view. In G. H. Bower (Ed.), The psychology of learning and motivation (Vol. 22, pp. 193-225). San Diego, CA: Academic Press. 
Heron, A., \& Chown, S. M. (1967). Age and function. Boston: Little-Brown.

Hertzog, C. (1989). Influences of cognitive slowing on age differences in intelligence.

Developmental Psychology, 25, 636-651.

Hertzog, C. (1992). Improving memory: The possible roles of metamemory. In D. J. Herrmann, H. Weingartner, A. Searleman, \& C. McEvoy (Eds.), Memory improvement: Implications for memory theory (pp. 61-78). New York: Springer.

Hertzog, C., Dixon, R. A., \& Hultsch, D. F. (1990). Relationships between metamemory, memory predications, and memory task performance in adults. Psychology and Aging, 5, 215-227.

Hertzog, C., Raskind, C. L., \& Cannon, C. J. (1986). Age-related slowing in semantic information processing speed: An individual differences analysis. Journal of Gerontology, $41,500-502$.

Horn, J. L. (1982). The theory of fluid and crystallized intelligence in relation to concepts of cognitive psychology and aging in adulthood. In F. I. M. Craik \& Trehub (Eds.), $\underline{\text { Aging }}$ and cognitive processes (pp. 237-278). New York: Plenum.

Horn, J. L., Donaldson, G., \& Engstrom, R. (1981). Apprehension, memory and fluid intelligence decline in adulthood. Research on Aging, 3, 33-84.

Huang, W. (1996). The role of working memoky in adult age differences in subjective organization. Unpublished master's thesis, West Virginia University, Morgantown, WV.

Hultsch, D. F., Hertzog, C., \& Dixon, R. A. (1987). Age differences in metamemory: Resolving the inconsistencies. Canadian Journal of Psychology, 41, 193-208.

Hultsch, D. F., Hertzog, C., \& Dixon, R. A. (1990). Ability correlates of memory performance in 
adulthood and aging. Psychology and Aging, 5, 356-368.

Hultsch, D. F., Hertzog, C., Dixon, R. A., \& Davidson, H. (1988). Memory self-knowledge and self-efficacy in the aged. In M. L. Howe \& C. J. Brainerd (Eds.), Cognitive development in adulthood: Progress in cognitive development research (pp. 65-92). New York: Springer.

James, W. (1981). The principles of psychology. In F. H. Brukhard, F. Bowers, \& I. K. Skurpskelis (Eds.), The works of William James (Vol. 1, pp. 380-386). Cambridge, MA: Harvard University Press. (Original work published 1905)

Jennings, J. R., Nebes, R. D., \& Yovetich, N. A. (1990). Aging increases the energetic demands of episodic memory: A cardiovascular analysis. Journal of Experimental Psychology: General, 119, 77-91.

Jones, H. E. (1956). Problems of aging in perceptual and intellective functions. In J. E. Anderson (Ed.), Psychological aspects of aging (pp. 135-139). Washington, DC: American Psychological Association.

Kahneman, D. (1973). Attention and effort. Englewood Cliffs, NJ: Prentice-Hall.

Kausler, D. H. (1994). Learning and memory in normal aging. San Diego: Academic Press.

Kersten, A., \& Salthouse, T. A. (1993). [Relations between time and accuracy in a continuous associative memory task]. Unpublished data.

Kliegl, R., Mayr, U., \& Krampe, R. (1994). Time-accuracy functions for determining process and person differences: An application to cognitive aging. Cognitive Psychology, 26, 134-164.

Kirchner, W. K. (1985). Age differences in short-term retention of rapidly changing information. 
Journal of Experimental Psychology, 55, 352-358.

Kyllonen, P. C. (1995). CAM: A framework for cognitive ability measurement. In D. Detterman (Ed.), Current topics in human intelligence: Theories of intelligence. (pp. 213-237) Norwood, NJ: Ablex.

Kyllonen, P. C. (1993). Aptitude testing inspired by information processing: A test of the foursources model. Journal of General Psychology, 120, 375-405.

Kyllonen, P. C., \& Christal, R. E. (1989). Cognitive modeling of learning abilities: A status report of LAMP. In R. Dillon \& J. Pellegrino (Eds.), Testing: Theoretical and applied issues. (pp. 146-173) New York: Freeman.

Kyllonen, P. C., \& Stephens, D. L. (1990). Cognitive abilities as determinants of success in acquiring logic skill. Learning and Individual Differences, 2, 129-160.

Kyllonen, P. C., Tirre, W. C., \& Christal, R. E. (1991). Knowledge and processing speed as determinants of associative learning. Journal of Experimental Psychology: General, 120, $57-79$.

Lachman, M. E., \& Leff, R. (1989). Perceived control and intellectual functioning in the elderly: A 5-year longitudinal study. Developmental Psychology, 25, 722-728.

Lachman, M. E., Steinberg, E., \& Trotter, S. (1987). Effects of control beliefs and attributions on memory self-assessments and performance. Psychology and Aging, 2, 266-271.

Langer, E. J., Avorn, J. (1985). Impact of the psychosocial environment of the elderly on behavioral and health outcomes. In B. B. Hess \& E. W. Markson (Eds.) Growing old in America: New perspectives on old age. (pp. 462-473) New Brunswick, NJ: Transaction Publishers.. 
Le Breck, D. B., \& Baron, A. (1987). Aging and practice effects in continuous recognition memory. Journal of Gerontology, 42, 89-91.

Leech, S., \& Witte, K. L. (1971). Paired-associate learning in elderly adults as related to pacing and incentive conditions. Developmental Psychology, 5, 174-180.

Light, L. L. (1991). Memory and aging: Four hypotheses in search of data. Annual Review of Psychology, 421, 333-376.

Light, L. L., \& Anderson, P. A. (1985). Working-memory capacity, age, and memory for discourse. Journal of Gerontology, 40, 737-771.

Light, L. L., \& Capps, J. L. (1986). Comprehension of pronouns in young and older adults. Developmental Psychology, 22, 580-585.

Lorsbach, T. C., \& Simpson, G. B. (1984). Age differences in the rate of processing in short-term memory. Journal of Gerontology, 39, 309-314.

Mäntylä, T., \& Bäckman, L. (1992). Aging and memory for expected and unexpected objects in real-world settings. Journal of Experimental Psychology: Learning, Memory, and Cognition, 18, 1298-1309.

Madden, D. J., Blumenthal, J. A., Allen, P. A., \& Emery, C. F. (1989). Improving aerobic capacity in healthy older adults does not necessarily lead to improved cognitive performance. Psychology and Aging, 4, 307-320.

Madden, D. J., \& Nebes, R. D. (1980). Aging and the development of automaticity in visual search. Developmental Psychology, 16, 377-384.

MacKay, D. G., \& Burke, D. M. (1990). Cognition and aging: a theory of new learning and the use of old connections. In T. M. Hess (Ed.) Aging and Cognition: Knowledge 
organization and utilization (pp. 213-264). Amsterdam: North-Holland.

Marsh, G. R. (1975). Age differences in evoked potential correlates of a memory scanning process. Experimental Aging Research, 1, 3-16.

Mayr, U., \& Kliegl, R. (1993). Sequential and coordinative complexity: Age-based processing limitations in figural transformations. Journal of Experimental Psychology: Learning, Memory, and Cognition, 19, 1297-1320.

Morris, R. G., Gick, M. L., \& Craik, F. 1. M. (1988). Processing resources and age differences in working memory. Memory and Cognition, 16, 362-366.

Morris, R. G., Gick, M. L., \& Craik, F. 1. M. (1990). Age differences in working memory tasks: The role of secondary memory and central executive system. Quarterly Journal of Experimental Psychology, 42A, 67-86.

Navon, D. (1984). Resources-A theoretical soup stone. Psychological Review, 91, 216-234.

Nestor, P. G., Parasuraman, R., \& Haxby, J. V. (1989). Attentional costs of mental operations in young and old adults. Developmental Neuropsychology, 5, 141-158.

Nettelbeck, T., \& Rabbitt, P. M. A. (1992). Aging, cognitive performance and mental speed. Intelligence, 16, 189-205.

Norman, D. A., \& Bobrow, D. G. (1975). On data-limited and resource-limited processes. Cognitive Psychology, 7, 44-64.

Okun, M. A., \& DiVesta, F. J. (1976). Cautiousness in adulthood as a function of age and instructions. Journal of Gerontology, 31, 571-576.

Okun, M.A., \& Elias, C. S. (1977). Cautiousness in adulthood as a function of age and instructions. Journal of Gerontology, 32, 451-576. 
Paivio, A., Yuille, J. C., \& Madigan, S. A. (1968). Concreteness, imagery, and meaningfulness values for 925 nouns. Journal of Experimental Psychology, 1968, 76, 1-25.

Park, D. C., \& Shaw, R. J. (1992). Effects of environmental support on implicit and explicit memory in younger and older adults. Psychology and Aging 7, 632-642.

Park, D. C., Puglisi, J. T., \& Smith, A. D. (1986). Memory for pictures: Does an age-related decline exist? Psychology and Aging, 1, 11-17.

Park, D. C., Smith, A. D., Lautenschlager, G., Earles, J. L., Frieke, D., Zwahr, \& Gaines, C. L. (1996). Mediations of long-term memory performance across the life span. Psychology and Aging, 11, 621-637.

Park, D. C., Smith, A. D., Morrell, R. W., Puglisi, J. T., \& Dudley, W. N. (1990). Effects of contextual integration on recall of pictures by older adults. Journal of Gerontology: Psychological Science, 45, P52-P57.

Pena, C. M., \& Tirre, W. C. (1992). Cognitive factors involved in the first stage of programming skill acquisition. Learning and Individual Differences, 4, 311-334.

Perlmutter, M. (1978). What is memory aging the aging of? Developmental Psychology, 14 330345.

Petros, T. V., Zehr, H. D., \& Chabot, R. J. (1983). Adult age differences in accessing and retrieving information from long-time memory. Journal of Gerontology, 38, 589-592.

Plude, D. J., \& Hoyer, W. J. (1981). Adult age differences in visual search as a function of stimulus mapping and processing load. Journal of Gerontology, 36, 224-231.

Plude, D. J., Hoyer, W. J., \& Lazar, J. (1982). Age, response complexity, and target consistency in visual search. Experimental Aging Research, 8, 99-102. 
Puglishi, J. T. (1986). Age-related slowing in memory search for three-dimensional objects. Journal of Gerontology, 35, 72-78.

Puglishi, J. T., Park, D. C., Smith, A. D., \& Dudley, W. N. (1987). Age differences in encoding specificity. Journal of Gerontology: Psychological Science, 43, P145-P150.

Rabbitt, P. (1993). Does it all go together when it goes? The Nineteenth Bartlett Memorial Lecture. Quarterly Journal of Experimental Psychology, 46A, 385-434.

Rabinowitz, J. C. (1988). Age deficits in recall under optimal study condition. Psychology and Aging, 4, 378-380.

Rabinowitz, J. C., Craik, F. I. M., \& Ackerman, B. P. (1982). A processing resource account of age differences in recall. Canadian Journal of Psychology, 36, 325-344.

Rankin, J. L., \& Collins, M. (1985). Adult age differences in memory elaboration. Journal of Gerontology, 40, 451-458.

Rankin, J. L., \& Collins, M. (1986). The effects of memory elaboration on adult age differences in incidental recall. Experimental Aging Research, 12, 231-234.

Rankin, J. L., \& Firnhaber, S. (1986). Adult age differences in memory changes with age: Effects of distinctive and common encodings. Experimental Aging Research, 12, 141-146.

Rees, J. N., \& Botwinick, J. (1971). Detection and decision factors in auditory behavior of the elderly. Journal of Gerontology, 26, 133-136.

Reese, H. W. (in press). Problems of statistical inference. Mexican Journal of Behavior Analysis. Reese, H. W. (1997). Counterbalancing and other uses of repeated-measures Latin-square designs: An analyses and interpretations. Journal of Experimental Child Psychology, 64, 137-158. 
Reese, H. W. (1970). Multiple comparison methods [comment]. American Psychologist, 25, 365366.

Salthouse, T. A. (1980). Age and memory: Strategies for localizing the loss. In L. W. Poon, J. L. Fozard, L. Cermak, D. Arenberg, \& L. W. Thompson (Eds.), New directions in memory and aging (pp. 47-65). Hillsdale, NJ: Erlbaum.

Salthouse, T. A. (1982). Adult cognition: An experimental psychology of human aging. New York: Springer-Verlag.

Salthouse, T. A. (1985a). Speed of behavior and its implications for cognition. In J. E. Birren \& K. W. Schaie (Eds.), Handbook of the psychology of aging ( $2^{\text {nd }}$ ed., pp. 400-426). New York: Van Nostrand Reinhold.

Salthouse, T. A. (1985b). A theory of cognitive aging. Amsterdam: North-Holland.

Salthouse, T. A. (1988). Initializing the formalization of theories of cognitive aging. Psychology and Aging, 3, 1-16.

Salthouse, T. A. (1991). Theoretical perspectives on cognitive aging. Hillsdale, NJ: Erlbaum.

Salthouse, T. A. (1992). Mechanisms of age-cognition relations in adulthood. Hillsdale, NJ: Erlbaum.

Salthouse, T. A. (1993). Speed mediation of adult age differences in cognition. Developmental Psychology, 29, 722-738.

Salthouse, T. A. (1994). The nature of the influence of speed on adult age differences in cognition. Developmental Psychology, 30, 240-259.

Salthouse, T. A. (1996). The processing-speed theory of adult age differences in cognition. Psychological Review, 103, 403-428. 
Salthouse, T. A., \& Babcock, R. L. (1991). Decomposing adult age differences in working memory. Developmental Psychology, 27, 763-776.

Salthouse, T. A., \& Kail, R. (1983). Memory development throughout the lifespan: The role of processing rate. In P. B. Baltes and O. G. Brim (Eds.), Life-span development and behavior (Vol. 5, pp. 89-116). New York: Academic Press.

Salthouse, T. A., \& Lichty, W. (1985). Tests of the neural noise hypothesis of age-related cognitive change. Journal of Gerontology, 40, 443-450.

Salthouse, T. A., \& Mitchell, D. R. D. (1989). Structural and operational capacities in integrative spatial ability. Psychology and Aging, 4, 480-486.

Salthouse, T. A., Mitchell, D. R. D., Skovronek, E., \& Babcock, R. L. (1989). Effects of adult age and working memory on reasoning and spatial abilities. Journal of Experimental Psychology: Learning, Memory, and Cognition, 15, 507-516.

Salthouse, T. A., \& Skovronek, E. (1992). Within-context assessment of age differences in working memory. Journal of Gerontology: Psychological Sciences, 47, 110-120.

Salthouse, T. A., \& Somberg, B. L. (1982a). Isolating the age deficit in speeded performance. Journal of Gerontology, 37, 59-63.

Salthouse, T. A., \& Somberg, B. L. (1982b). Skilled performance: The effects of adult age and experience on elementary processes. Journal of Experimental Psychology: General, 111, 176-207.

Sanders, R. E., Murphy, M. D., Schmitt, F. A., \& Walsh, K. K. (1980). Age differences in free recall rehearsal strategies. Journal of Gerontology, 35, 550-558.

Schaie, K. W., \& Willis, S. L. (1991). Adult development and aging ( $3^{\text {rd }}$ ed.). New York: Harper- 
Collins.

Scogin, F. R., Storandt, M., \& Lott, C. L. (1985). The relationship of memory complaint to memory evaluation, affective status, and memory performance in older adults. $\underline{\text { Journal of }}$ Gerontology, 40, 562-568.

Shute, V. J., \& Kyllonen, P. C. (1990). Modeling individual differences in programming skill acquisition (AFHRL Technical Paper No. 90-76). Brooks Air Force Base, TX: Air Force Human Resources Laboratory.

Spilich, G. J. (1985). Discourse comprehension across the span of life. In N. Charness \& J. E. Birren (Eds.), Behavior, aging and the nervous system (pp. 366-400). Springfield, IL: Charles C Thomas.

Stine, E. L., Wingfield, A., \& Poon, L. W. (1986). How much and how fast: Rapid processing of spoken languages in later adulthood. Psychology and Aging, 1, 272-279.

Strayer, D. L. Wickens, C. D., \& Braune, R. (1987). Adult age differences in the speed and capacity of information processing: 2 . An electrophysiological approach. Psychology and Aging, 2, 99-110.

Talland, G. A. (1967). Age and the immediate memory span. Gerontologist, 7, 4-9.

Talland, G. A. (1968). Age and the span of immediate recall. In G. A. Talland (Ed.), Modern trends in psychological medicine II (pp. 24-52). New York: Appleton-Century-Crofts.

Taub, H. A. (1968). Age differences in memory as a function of rate of presentation, order of report, and stimulus organization. Journal of Gerontology, 23, 159-164.

Thomas, J. C., Waugh, N. C., \& Fozard, J. L. (1978). Age and familiarity in memory scanning. Journal of Gerontology, 33, 528-533. 
Tomer, A., \& Cunningham, W. R. (1993). The structure of cognitive speed measures in old and young adults. Multivariate Behavioral Research, 28, 1-24.

Treat, N. J., \& Reese, H. W. (1976). Age, pacing, and imagery in paired-associate learning. Developmental Psychology, 12, 119-124.

Wallach, M. A., \& Kogan, N. (1961). Aspects of judgment and decision-making: interrelationships and changes with age. Behavior Science, 6,. 23-36.

Waugh, N. C., Fozard, J. L. \& Thomas, J. C. (1978). Retrieval time from different memory stores. Journal of Gerontology, 33, 718-724.

Welford, A. T. (1958). Ageing and human skills. London: Oxford University Press.

Welford, A. T. (1962). On changes of performance with age. Lancet, 17, 335-339.

Welford, A. T. (1980). Thirty years of psychological research on age and work. Journal of Occupational Psychology, 49, 129-138.

West, R. L., \& Boatwright, L. K. (1983). Age differences in cued recall and recognition under varying encoding and retrieval condition. Experimental Aging Research, 9, 185-189.

White, N., \& Cunningham, W. R. (1987). The age comparative construct validity of speeded cognitive factors. Multivariate Behavioral Research, 22, 249-265.

Wickelgren, W. A., \& Norman, D. A. (1966). Strength models and serial position in short-term recognition memory. Journal of Mathematical Psychology, 3 , 316-347.

Wingfield, A. (1980). Attention, levels of processing, and state-dependent recall. In L. W. Poon J. L. Fozard, L. S. Cermak, D. Arenberg, \& L. W. Thompson (Eds.), New directions in memory and aging (pp. 135-141). Hillsdale, NJ: Erlbaum.

Wingfield, A., \& Stine, E. A. L. (1989). Modeling memory processes: Research and theory on 
memory and aging. In G. C. Gilmore, P. J. Whitehouse, \& M. L. Wykle (Eds.), Memory, aging, and dementia: Theory, assessment and treatment (pp. 4-40). New York: Springer.

Witt, S. J., \& Cunningham, W. R. (1979). Cognitive speed and subsequent intellectual development: A longitudinal investigation. Journal of Gerontology, 34, 540-546.

Woltz, D. J. (1988). An investigation of the role of working memory in procedural skill acquisition. Journal of Experimental Psychology: General, 117, 319-331.

Wright, R. E. (1981). Aging, divided attention, and processing capacity. Journal of Gerontology, $\underline{36,605-614 .}$

Zacks, R. T., \& Hasher, L. (1988). Capacity theory and the processing of inferences. In L. L. Light \& D. M. Burke (Eds.), Language, memory and aging (pp. 154-170). New York: Cambridge University Press.

Zelinski, E. M., Schaie, K. W., \& Gribben, K. (1977, August). Omission and commission errors: Task-specific adult life-span differences. Paper presented at the meeting of the American Psychological Association, San Francisco. 
83

\section{Appendix A}

\section{Word Lists}

\section{Table A1}

Lists of 1-syllabus words

\begin{tabular}{ll}
\hline Words & Frequency \\
\hline
\end{tabular}

List A

\begin{tabular}{lc}
\hline & \\
boss & 23 \\
dirt & 21 \\
joke & 32 \\
ink & 20 \\
toast & 20 \\
stub & 5 \\
truce & 3 \\
air & AA \\
time & AA \\
car & AA \\
gift & A \\
dust & A \\
fault & A \\
fur & A \\
style & A \\
wine & A
\end{tabular}

List B

\begin{tabular}{lr}
\hline cane & 19 \\
fork & 31 \\
link & 24 \\
greed & 3 \\
tank & 19 \\
yacht & 2 \\
fox & 25 \\
death & AA \\
cell & A \\
corn & A \\
mind & AA \\
door & AA \\
flag & A \\
nail & A \\
shock & A \\
wheat & A
\end{tabular}

Lists of 3-syllable words

\begin{tabular}{ll}
\hline Word & Frequency \\
\hline
\end{tabular}

List A

$\begin{array}{lr}\text { advantage } & \text { A } \\ \text { devotion } & 21 \\ \text { engagement } & 24 \\ \text { evidence } & \mathrm{A} \\ \text { fisherman } & 26 \\ \text { gymnastics } & 3 \\ \text { hospital } & \mathrm{A} \\ \text { industry } & \mathrm{AA} \\ \text { library } & \mathrm{A} \\ \text { material } & \mathrm{AA} \\ \text { direction } & \mathrm{AA} \\ \text { appearance } & \mathrm{AA} \\ \text { profession } & 28 \\ \text { property } & \mathrm{A} \\ \text { institute } & \mathrm{A} \\ \text { jeopardy } & \mathrm{A}\end{array}$

List B

$\begin{array}{lr}\text { furniture } & \text { A } \\ \text { animal } & \text { AA } \\ \text { convention } & \mathrm{A} \\ \text { enterprise } & 21 \\ \text { expression } & \mathrm{A} \\ \text { gallery } & 28 \\ \text { happiness } & \mathrm{A} \\ \text { gentleman } & \mathrm{AA} \\ \text { magazine } & \mathrm{A} \\ \text { officer } & \mathrm{AA} \\ \text { camouflage } & 2 \\ \text { vegetable } & \mathrm{A} \\ \text { permission } & 22 \\ \text { gratitude } & 22 \\ \text { intellect } & 27 \\ \text { aptitude } & 2\end{array}$


Table A2

\section{List Characteristics}

\begin{tabular}{lcccc} 
& \multicolumn{2}{c}{ 1-syllable } & \multicolumn{2}{c}{ 3-syllable } \\
\cline { 2 - 4 } Variable & List A & List B & List A & List B \\
\hline Frequency range & $3-32$ & $2-31$ & $2-28$ & $2-28$ \\
Frequency mean & 17.7 & 17.6 & 17.8 & 17.7 \\
Number of A & 6 & 6 & 7 & 7 \\
Number of AA & 3 & 3 & 3 & 3 \\
\hline
\end{tabular}




\section{Appendix B}

Latin-square Confoundings in this Study

1. Task x Order confounded with syllable.

\begin{tabular}{lll} 
Order & Dual task & Control task \\
\hline First task & 1-syllable & 3-syllable \\
Second task & 3-syllable & 1-syllable \\
\hline
\end{tabular}

2. Task $x$ List confounded with syllable

\begin{tabular}{lll} 
List & Dual task & Control task \\
\hline A & 1-syllable & 3-syllable \\
B & 3-syllable & 1-syllable \\
\hline
\end{tabular}

3. List confounded with order

\begin{tabular}{lll} 
Order & Dual task & Control task \\
\hline First task & A & A \\
Second task & B & B \\
\hline
\end{tabular}

4. Task x syllable confounded with order

\begin{tabular}{lll} 
Syllable & Dual task & Control task \\
\hline 1-syllable & First & Second \\
3-syllable & Second & First \\
\hline
\end{tabular}

5. Task x syllable confounded with list

\begin{tabular}{lll} 
Syllable & Dual task & Control task \\
\hline 1-syllable & A & B \\
3-syllable & B & A \\
\hline
\end{tabular}

6. Syllable $\mathrm{x}$ list confounded with task

\begin{tabular}{lll} 
List & 1-syllable & 3-syllable \\
\hline A & Dual & Control \\
B & Control & Dual \\
\hline
\end{tabular}


Appendix C

Demographic Questionnaire

1. Birthdate: Month

Day

Year

2. Sex: (circle one) Male Female

3. Circle the highest level of education you have completed:
a. Grade School/
High School:
$1 \mathrm{st}$
2nd 3rd
4 th 5 th
6th
7 th
8th 9th 10th
11th 12th
b. Trade, Business
or Technical
School:
1 yr. 2 yr. 3 yr.
4 yr.
$5 \mathrm{yr} .6 \mathrm{yr}$.
c. College:
1 yr. 2 yr. 3 yr.
4 yr.
$5 \mathrm{yr}$.
d. Graduate School:
1 yr. 2 yr. 3 yr.
$4 \mathrm{yr}$.
5 yr. 6 yr.
$7 \mathrm{yr}$.

4. Marital Status: (Circle one)
a. Single
c. Divorced
e. Separated
b. Widowed
d. Married

5. What is your native language? That is, what language was spoken in your home when you were a child?

If your native language is not English, at what age did you learn English?

6. Please list any medication you are now taking:

7. Compared to other people my age, I believe my health to be: (circle one)

\begin{tabular}{lcccccc}
1 & 2 & 3 & 4 & 5 & 6 & 7 \\
\hline $\begin{array}{l}\text { very } \\
\text { good }\end{array}$ & good & moderately & average & moderately & poor & very \\
& & good & & poor & & poor
\end{tabular}


VITA

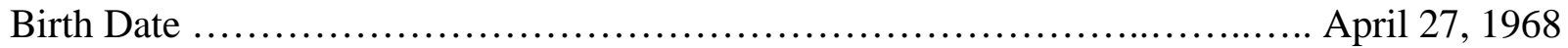

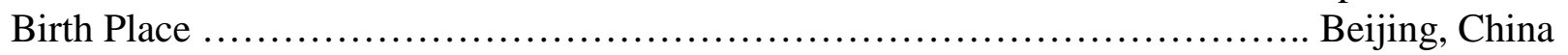

B.S. Chemistry ….................................Southwest China Normal University, 1990

M.Ed. Educational Psychology ....................... Southwest China Normal University, 1993

M.A. Developmental Psychology ............................... West Virginia University, 1996

M.S. Computer Science ..................................... West Virginia University, 1998 


\begin{abstract}
Both experimental and individual differences approaches were used in the present study to investigate the effects of processing resources, cautiousness, and memory self-efficacy on adult age differences in free recall performance. A total of 80 young college students (mean age $=$ 23 years) were used for the experimental manipulations; 40 older adults (mean age $=75$ years) served as a comparison group. The experimental manipulations were based on a 2 (sex) by 2 (processing speed) by 2 (cautiousness) by 2 (working memory) mixed design. Cautiousness was manipulated by monetary incentive and punishment. Age-related reduction in working memory capacity was simulated by using a the concurrent digit load during learning. Age-related slowness was simulated by using words with multiple syllables. Participants' speed of information processing was measured by the Digit Symbol Substitution Test and the Finding A's test. Working memory was assessed by the Forward and Backward Digit span and Computation-span tests. Memory self-efficacy was measured by the Memory Self-efficacy Questionnaire. It was found that all three experimental manipulations produced similar effects on the younger adults' recall performance. Furthermore, the combined effects of speed, cautiousness, and working memory in the young reduced their recall performance to the same level of the old in several position of the serial position curve, which implied that the age-related differences in free recall are caused by all three factors. In addition, the individual-differences analyses revealed that when speed and working memory were controlled, age group no longer predicted individual differences in recall performance. Age differences in free recall performance were mediated by speed and working memory.
\end{abstract}


Signature Page

\section{Approval of Examining Committee}

Stanley H. Cohen, Ph. D.

Barry A. Edelstein, Ph. D.

Constance E. Toffle, Ph. D.

Richard T. Walls, Ph. D.

Date

Hayne W. Reese, Ph. D. (Chair) 